OPEN ACCESS

Edited by: Longhuo Wu,

Gannan Medical University, China

Reviewed by:

Qingjia Chi,

Wuhan University of Technology,

China

Maurice Collins,

University of Limerick, Ireland

${ }^{*}$ Correspondence:

Yimei Hu

huyimei@cdutcm.edu.cn

Specialty section: This article was submitted to

Ethnopharmacology,

a section of the journal

Frontiers in Pharmacology

Received: 04 October 2021 Accepted: 08 December 2021

Published: 31 January 2022

Citation:

Mu P, Feng J, Hu Y, Xiong F, Ma X and Tian L (2022) Botanical Drug Extracts Combined With Biomaterial Carriers for Osteoarthritis Cartilage Degeneration Treatment: A Review of 10 Years

of Research.

Front. Pharmacol. 12:789311. doi: 10.3389/fphar.2021.789311

\section{Botanical Drug Extracts Combined With Biomaterial Carriers for Osteoarthritis Cartilage Degeneration Treatment: A Review of 10Years of Research}

\author{
Panyun $\mathrm{Mu}^{1}$, Jie Feng ${ }^{1}$, Yimei $\mathrm{Hu}^{2 *}$, Feng Xiong ${ }^{1}, \mathrm{Xu} \mathrm{Ma}^{1}$ and Linling Tian ${ }^{1}$ \\ ${ }^{1}$ Department of Clinical Medicine, Chengdu University of Traditional Chinese Medicine, Chengdu, China, ${ }^{2}$ Department of \\ Orthopedics, Hospital of Chengdu University of Traditional Chinese Medicine, Chengdu, China
}

Osteoarthritis (OA) is a long-term chronic arthrosis disease which is usually characterized by pain, swelling, joint stiffness, reduced range of motion, and other clinical manifestations and even results in disability in severe cases. The main pathological manifestation of $\mathrm{OA}$ is the degeneration of cartilage. However, due to the special physiological structure of the cartilage, once damaged, it is unable to repair itself, which is one of the challenges of treating OA clinically. Abundant studies have reported the application of cartilage tissue engineering in OA cartilage repair. Among them, cell combined with biological carrier implantation has unique advantages. However, cell senescence, death and dedifferentiation are some problems when cultured in vitro. Botanical drug remedies for OA have a long history in many countries in Asia. In fact, botanical drug extracts (BDEs) have great potential in anti-inflammatory, antioxidant, antiaging, and other properties, and many studies have confirmed their effects. BDEs combined with cartilage tissue engineering has attracted increasing attention in recent years. In this review, we will explain in detail how cartilage tissue engineering materials and BDEs play a role in cartilage repair, as well as the current research status.

Keywords: osteoarthritis, botanical drug, extracts, cartilage, tissue engineering, biomaterial carriers

\section{INTRODUCTION}

Osteoarthritis (OA) is a progressive arthrosis disease (Crivelli et al., 2019), the main pathophysiological features of which include cartilage defects, synovitis, osteophyte formation, and subchondral bone damage (Yeh et al., 2015; Wang et al., 2018). OA patients suffer from joint pain and stiffness, difficulty in movement, and ultimately disability (Wang et al., 2018; Jin, 2020), which significantly affects their quality of life (Rahimi et al., 2021), especially for the elderly (Kann et al., 2016), and places a huge economic burden on their families and society (Wang et al., 2018; Jin, 2020). According to the World Health Organization, more than $10 \%$ of people under the age of 60 worldwide suffer from OA (Wang et al., 2018). By 2032, the number of people over the age of 45 suffering from OA will increase from 25 to $29 \%$, and the peak of incidence will be around the age of 75 (Qin et al., 2020). 


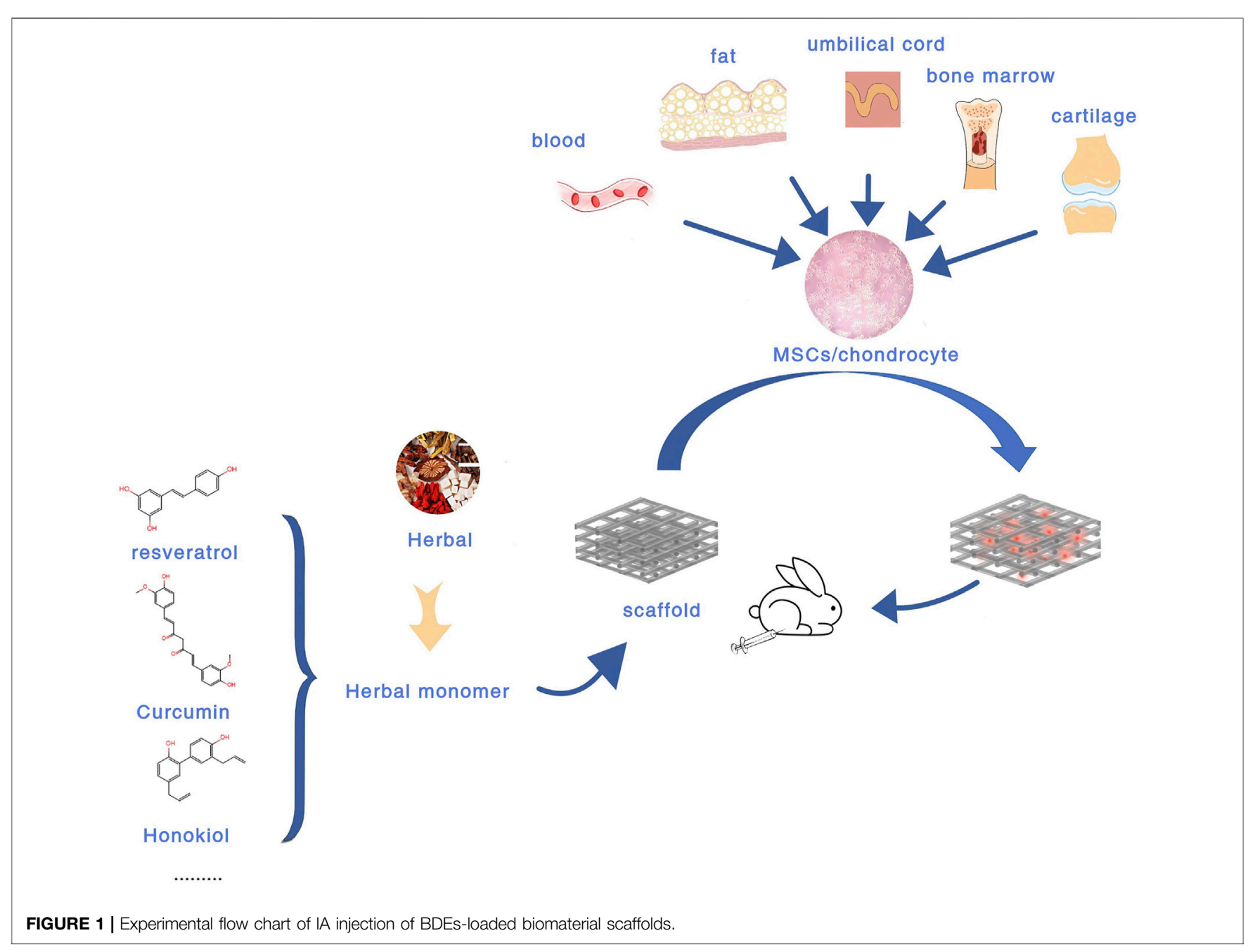

\subsection{Ultrastructure of Bone and Joint, and Pathogenesis of OA}

In a joint, the articular cartilage, calcified cartilage, subchondral cortex, and trabecular bone form biological complexes called "osteochondral units" (Goldring and Goldring, 2016). The articular cartilage is mainly composed of extracellular matrix (ECM) and chondrocytes (1-2\%). The ECM consists mainly of Type II collagen (COL2), glycosaminoglycan (GAG), aggrecan (ACAN), elastin fibrils, and 70\% water (Goldring and Goldring, 2016; Jin, 2020) and provides tensile and elastic force for the articular cartilage (Crivelli et al., 2019) to maintain the proper biomechanical function of the joint. The development, maintenance, and repair of the ECM are controlled by chondrocytes derived from highly specialized and metabolically active mesenchymal stem cells (MSCs). The shape, number, and size of chondrocytes, stiffness of the cartilage, ECM composition, and content of proteoglycan, COL2, and water in the ECM vary with the anatomical regions of the articular cartilage (Rai et al., 2017)

Articular cartilage can be damaged by daily wear and abnormal mechanical load (Xia et al., 2014). With the progression of $\mathrm{OA}$, a disintegrin and metalloproteinase with thrombospondin motifs 5 (ADAMTS5) and matrix metalloproteinase 13 (MMP13) are the main enzymes causing cartilage damage (Wang et al., 2013; Miller et al., 2016; Jin et al., 2020a). In the early stages of OA, inflammatory stimuli induce the cartilage and synovial cells to secrete these enzymes. Steoarthritic chondrocytes mediate the production of inflammatory mediators, including interleukin 1 (IL-1), tumor necrosis factor (TNF), prostaglandins, and nitric oxide (NO) through the nuclear factor-kappa B (NF-kB) signaling pathway (Charlier et al., 2019). IL-1 $\beta$ and TNF- $\alpha$ are effective inducers of matrix metalloproteinases (MMPs). Among them, proteases MMP1, MMP3, and MMP13 inhibit proteoglycan and collagen synthesis, mediate chondrocyte apoptosis, and promote cartilage inflammation (Abramson, 2008; Blanco et al., 2011; Oliveira Silva et al., 2020).

\subsection{Treatment Status of Osteoarthritis}

The lack of vascular and aneural tissue in articular cartilage gives it a limited intrinsic self-repair ability (Sheu et al., 2013; Lima et al., 2019), which makes the treatment of articular cartilage 


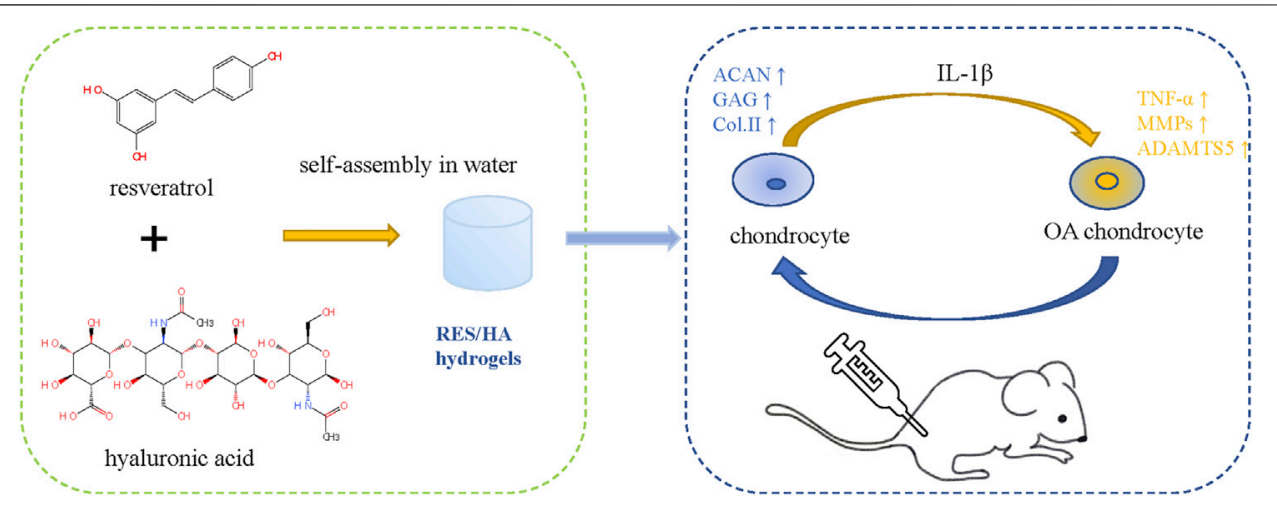

FIGURE 2 | Schematic diagram of chondrocyte regulation of HA-based hydrogel combined with BDEs.

defects an extremely difficult clinical problem (Makris et al., 2015). The current methods include conservative and nonconservative treatments. The conservative treatments include non-pharmacologic, pharmacologic, and alternative therapies (Madry et al., 2011; Kang et al., 2020), while nonconservative therapeutic strategies mainly include bone marrow stimulation (Frehner and Benthien, 2018), autologous or allogeneic osteochondral transplantation (Bugbee et al., 2016; Di Martino et al., 2021), autologous chondrocyte implantation, and periosteum transplantation (Mistry et al., 2017). Although such treatments have been widely used in clinical practice, they still have obvious and inevitable limitations and deficiencies (Vinatier and Guicheux, 2016; Xu et al., 2020).

Drug therapies include nonsteroidal anti-inflammatory drugs (NSAIDs), opioids, and glucocorticoids. Most therapies are limited to symptomatic treatment aiming at relieving pain and improving joint function rather than inhibiting the progression of OA (Jin, 2020). However, the long-term use of such drugs can cause serious adverse reactions such as gastrointestinal reactions and osteoporosis (Crivelli et al., 2019; Shi et al., 2019). Beyond oral administration, other routes have been developed for the treatment of OA. Different from other diseases, OA is limited to one or more joints, which offers a special opportunity for local intra-articular (IA) drug injection. IA allows the delivery of therapeutic drugs directly to the diseased joint at very high concentrations; moreover, it limits the absorption of drugs into the systemic circulation, which reduces systemic toxicity. Thus, compared with the systemic approach, a smaller dose can achieve a therapeutic effect similar to that of oral administration (Burt et al., 2009; Jones et al., 2019). IA injections of hyaluronic acid (HA) or glucocorticoids have been used to relieve knee OA (KOA) pain (Berenbaum et al., 2012). However, the main limitation of IA injection is the rapid elimination of the drug from the articular cavity. Studies have shown that small-molecule drugs ( $\mathrm{MW}<10 \mathrm{kDa}$ ) can be removed from the synovial fluid by lymphatic drainage within $5 \mathrm{~h}$ of injection (Zhang et al., 2018; Jones et al., 2019), and thus multiple injections are required, which can lead to infection or joint disability. To control the release rate over a long period of time, a new biology-based drug delivery vector is needed (Chen et al., 2012).
Compared with the above treatment methods, tissue engineering composed of scaffolds, cells, and favorable growth factors has become the most promising treatment strategy for cartilage repair (Xu et al., 2020). Biodegradable tissue engineering scaffolds have attracted great attention in recent years by virtue of their many advantages (Ming et al., 2018). At the same time, tissue engineering methods are preferred for severe cartilage defects, congenital abnormalities, and elderly patients with limited inherent ability (Lima et al., 2019). Currently, there are various biomaterial scaffolds for cartilage defects, including hydrogels, nanoparticles, microspheres, liposomes, and so on (Lima et al., 2019; Jin, 2020; Xu et al., 2020). In terms of cell selection, the current research shows that chondrocytes and MSCs remain the main sources of seed cells in cartilage repair (Xu et al., 2020). However, the main drawback of using autologous chondrocytes is that when cultured in vitro, they are prone to dedifferentiate and develop into a fibroblast phenotype (Vinatier and Guicheux, 2016). (Figure 1 Experimental flow chart of intra-articular injection of BDEs loaded biomaterial scaffolds).

Growth factors play essential regulatory roles in cartilage development (Lecanda et al., 1997; Chen et al., 2020a). The most effective growth factor for inducing cartilage formation is transforming growth factor $\beta$ (TGF- $\beta$ ) (Makris et al., 2015). However, in vivo studies have shown that under continuous stimulation by TGF- $\beta 1$, adverse reactions such as synovial fibrosis, endochondral osteogenesis, and hypertrophic scarring were observed. On the other hand, growth factors can only release their maximum potential at the injured site and can easily become inactivated under physiological conditions (Chen et al., 2020a). Moreover, the use of growth factors is limited due to their complex extraction process, high cost, and low yield (Wildemann et al., 2007). At present, it is urgent to explore a simple, effective, safe, and cheap bioactive substance to replace growth factors and meet the actual demands of cartilage repair (Kankala et al., 2018; Jin, 2020).

There are many reviews on the repair of cartilage defects. Based on preclinical and clinical studies, Theodoridis et al. (2021) reviewed the research status and limitations of cartilage tissue engineering as a cartilage repair strategy from the aspects of 
biomaterial selection, cell implantation, scaffold performance and structure, local biological stimulation, etc. Makris et al. (2015) reviewed the current clinical use of articular cartilage surface defect repair technologies and the status of preclinical research on stent-based acellular or chondrocyte implantation technologies. Murphy et al. (2019) mainly discussed the repair technology of meniscus injury and the protective effects of meniscus repair on cartilage. Herbal therapy for OA has been reported in many related studies, and botanical drug extracts (BDEs) combined with scaffolds in the treatment of OA have also been the subject of a large number of studies. Compared to growth factors, BDEs have a wider range of sources, more accessibility, and greater costefficiency. Various studies have demonstrated their antiinflammatory, antioxidant, and cartilage protection properties. Many practices have studied the use of herbs in biotechnology in treating rheumatoid arthritis (RA) and OA (Buhrmann et al., 2020). However, the combination of BDEs with cartilage tissue engineering is rarely used in clinical practice and is mostly done in preclinical research. In this review, we will explain in detail how cartilage tissue engineering materials and BDEs play a role in cartilage repair, as well as the current research status (Figure 2 Schematic diagram of chondrocyte regulation of HA - based hydrogel combined with BDEs).

\subsection{Botanical Drug Extracts}

In the latest guidelines for OA, NSAIDs are recommended as a high-grade evidence-based therapy (Bannuru et al., 2019), but patients are prone to adverse reactions after taking such drugs. In recent years, certain advancements have been made in the treatment of $\mathrm{OA}$ with botanical drug remedies. In relevant meta-analyses, it has been found that botanical drug can relieve pain and improve the range of motion in patients with KOA (Cameron and Chrubasik, 2014), and the incidence of adverse reactions is low (Chen et al., 2016a). We searched in the PubMed database for "osteoarthritis," "arthritis," "tissue engineering," "cartilage tissue engineering," "biomaterials, Chinese herbal medicine," "scaffolds," "nanoparticles," and "hydrogels." Reviews, conference papers, and studies (those did not include both BDEs and carriers) were excluded. Finally, 31 related articles were selected through reading headlines, abstracts, and full texts. We then classified the $\mathrm{BDEs}$ in the literature (including flavonoids, polyphenols, alkaloids, saponins, and others). By summarizing the effect of plant drug extract combined with biomaterial carrier on the repair of OA cartilage injury, its mechanism, and current research status, we provide a theoretical basis for ideas and directions of future research.

\section{FLAVONOIDS}

\subsection{Quercetin}

Quercetin (QUE), an abundant bioflavonoid, is widely distributed in the plant kingdom as a secondary plant metabolite. It is also a common component of the human diet, being found in onions, apples, and so on (Andres et al., 2018). QUE has effective antioxidant, antiproliferative, and free radical scavenging properties (Yeung et al., 2021), as well as being able to alleviate pain (Britti et al., 2017) caused by arthritis (Kanzaki et al., 2012; Wei et al., 2019). A large amount of evidence shows that QUE can delay the occurrence and development of OA (Britti et al., 2017; Feng et al., 2019a; Hu et al., 2019; Ma et al., 2019). In the animal model of OA, QUE can raise the production of superoxide dismutase (SOD), attenuate reactive oxygen species (ROS) levels, reduce inflammation and oxidative stress, improve antioxidant defense, maintain the integrity of joint cartilage ECM, and reduce symptoms and arthritis (Qiu et al., 2018; Wei et al., 2019). QUE can inhibit the expression of chondrocyte matrix degradation protease and inflammatory mediators, reduce cartilage degradation and apoptosis in OA rats, and promote cartilage synthesis (Hu et al., 2019). Siard et al. (2016) showed that QUE significantly reduces the production of inflammatory cytokines by lymphocytes and is even more effective than common NSAIDs. However, due to its low bioavailability of oral administration, studies have reported no significant improvement in the treatment of arthritis with QUE (Bae et al., 2009; Javadi et al., 2014). Mok et al. (2020) injected QUE-loaded polypeptide-based hydrogel, namely methoxypoly(ethylene glycol)-l-poly(alanine) (mPEG-PA), into the knee joints of OA rats and found that the gradual release of QUE from the mPEG-PA hydrogel could be sustained over 28 days; in addition, the limb idleness index (LII) of the rats was significantly decreased after treatment with QUE $(50 \mu \mathrm{g})$ hydrogel at 4 and 8 weeks $(-0.27,-0.31)$. The Osteoarthritis Research Society International (OARSI) score shows that the international score of the QUE hydrogel group $(50 \mu \mathrm{g})$ was significantly lower than that of the control group $(p<0.01)$. These results suggest that the continuous use of QUE hydrogel $(50 \mu \mathrm{g})$ can relieve OA symptoms and delay the progression of KOA.

\subsection{Hesperetin}

Hesperetin (Hes), a flavonoid in the flavanone class extracted from citrus fruit (Muhammad et al., 2019), can inhibit osteoclast formation and promote the differentiation of osteoblasts, giving it potential for treating bone-related diseases (Ouyang et al., 2019). HES also has antioxidant and anti-inflammatory properties. The antioxidant activity of HES not only is limited to scavenging free radicals but also enhances the defense ability of antioxidant cells through the ERK/Nrf2 signaling pathway (Parhiz et al., 2015). Lin et al. (2020) found the anti-inflammatory effect of HES in OA lies in inhibiting the IL- $1 \beta$-induced expression of inflammatory factors, downregulating MMP13 and ADAMTS5, and upregulating COL2 and protein aggregation. There has been only one animal study that used HES combined with a cartilage tissue engineering scaffold. Ouyang et al. (2019) loaded HES into nanoparticles (HGdPDW). HGdPDW promoted the expression of ACAN, Sox9, and COL2A1 after IL-1 $\beta$ stimulation for 3 days $(p<0.05)$ but inhibited the expression of MMP13 and COL10A1 $(p<0.05)$, thus reducing apoptosis and inflammatory response. Magnetic resonance imaging (MRI)/ Interactive Video Information System (IVIS) bipeak imaging confirmed that HGdPDW has low cytotoxic and chondrogenic binding ability. HGdPDW treatment increases the 
articular cartilage thickness of the knee, preserves proteoglycan and collagen, and alleviates the progressive degeneration of articular cartilage in vivo. In addition, it can significantly improve the OARSI score of anterior cruciate ligament transection (ACLT) in OA mice $(p<0.05)$.

\subsection{Icariin}

Icariin (ICA), the main component of Epimedii Folium (Epimedium brevicornu Maxim., Epimedium sagittatum (Sieb. et Zucc.) Maxim., Epimedium pubescens Maxim., or Epimedium koreanum Nakai), is a typical flavonoid compound with antiinflammatory, anti-oxidative (Zuo et al., 2019), and boneprotective properties (Wang et al., 2020). ICA can treat OA through multiple pathways and targets. It increases the vitality of chondrocytes through reducing the inflammatory damage caused by NF- $\kappa$ B/HIF-2 $\alpha$ signaling (Wang et al., 2020); regulates chondrocyte autophagy by mediating the PI3K/Akt/ mTOR pathway (Tang et al., 2021) and inhibiting NF- $\kappa$; alleviates $\mathrm{OA}$ by inhibiting inflammatory cytokines and chondrocyte apoptosis (Liu et al., 2018a; Mi et al., 2018); upregulates the proliferation, osteogenic, and chondrogenic differentiation of bone marrow-derived MSCs (BMSCs); and protects BMSCs from apoptosis through the mitogen-activated protein kinase (MAPK) signaling pathway (Liu et al., 2020a). In a study on ICA and human OA fibroblast-like synoviocytes, it was found that ICA could inhibit the expression of IL-1 $\beta, M M P 4$, and glucose-regulated protein 78 (GRP78), which further reduces the inflammatory response (Pan et al., 2017). Thus, ICA is an effective candidate drug for the treatment of articular cartilage injury, and due to its low price, easy access, and reparative effects on osteochondral defects, it has earned the increasing attention of researchers.

There are two animal studies that used ICA combined with cartilage tissue engineering scaffolds. Kankala et al. (2018) printed porous three-dimensional (3D) sodium alginate (SA) and gel scaffolds with excellent mechanical strength. They then studied the physical characterizations and cytocompatibility of the scaffolds, and the effects of ICA on the growth of chondrocytes. With the extension of the incubation time in vitro, the content of GAG in chondrocytes increased gradually, and ICA $(10 \mu \mathrm{g} / \mathrm{ml})$ could significantly accelerate GAG secretion. However, there is no relevant animal model of OA to further verify the reparative effects of ICA combined with stents on OA cartilage defects. Li et al. (2012) used ICA/Type I collagen (ICA/COL) hydrogel encapsulated neonatal rabbit chondrocytes to construct engineering grafts. The results showed that ICA could significantly upregulate the expression of ACAN, Sox9, and COL2 (from 99.7 to 248\%), upregulate the synthesis of GAG and COL2, and accelerate the formation of cartilage tissue in the cell hydrogel structure. It could even improve the reparative efficiency of supercritical osteochondral defects in adult rabbit models and promote the fusion of newly formed cartilage and subchondral bone. Thus, ICA is a promising compound for cartilage repair and serves as a substitute for certain growth factors (Table 1).

\section{POLYPHENOLS}

\subsection{Resveratrol}

Resveratrol (RES) is a phytochemical found in grape and Reynoutria japonica Houtt. which acts on several cellular signaling pathways and has anti-inflammatory, antioxidant, and antiaging properties (Limagne et al., 2016; Wang et al., 2016; Oz et al., 2019; Yeung et al., 2019; Yuce et al., 2021). Elmali et al. (2007) showed that the IA injection of RES could mitigate synovitis cell infiltration and cartilage damage through the histopathological evaluation of the rabbit arthritis model. RES can prevent the degradation of proteoglycan and ACAN in cartilage tissue induced by advanced glycation end products (AGEs) (Liu et al., 2010); upregulate the expression of COL2; downregulate the expression of inducible NO synthase (iNOS) and MMP13 (Li et al., 2015); reduce the accumulation of ROS and hypoxia inducible factor- $\alpha$ (HIF-1 $\alpha$ ); and inhibit the MAPK signaling pathway to prevent inflammation and degeneration of the joints (Yang et al., 2018). RES can also effectively reverse IL-1 $\beta$-induced catabolic and inflammatory responses ( $\mathrm{Gu}$ et al., 2017) and significantly prevent OA cartilage damage by activating sirtuin 1 (SIRT1) to inhibit the expression of HIF-2 $\alpha$ and catabolic factors (Li et al., 2015; Wang et al., 2016; Abed et al., 2017). In addition, RES has a protective effect on subchondral bone, which is manifested in the promotion of the $\mathrm{Wnt} / \beta$-catenin and ERK1/2 signaling pathways to boost mesenchymal cell differentiation into osteoblasts (Abed et al., 2017).

Qin et al. (2017) have shown that the IA injection of RES promotes chondrocyte autophagy (via regulating the HIF1a-dependent MAPK/mTOR signaling pathway) and delays cartilage degeneration induced by medial meniscal instability surgery. Dietary RES supplementation can reduce paw edema and erythema in collagen-induced arthritis-OA (CIA-OA) model rats and mitigate the invasion of inflammatory cells and cartilage degeneration around the joints (Oz et al., 2019). The intraperitoneal injection of RES (5 or $10 \mathrm{mg} / \mathrm{kg})$ in monosodium iodoacetate-induced arthritis-OA (MIA-OA) rats significantly reduced mechanical, thermal, and cold hyperalgesia and increased vertical and horizontal movements (Wang et al., 2016). At the same time, a clinical study showed that treatment with RES improved WOMAC scores (pain, stiffness, and body function) (Hussain et al., 2018). These results suggest that RES may be a potential analgesic agent that can reduce pain and discomfort in KOA patients and improve their general condition and life quality. The anti-inflammatory effects of RES have been studied in both humans and animals. Due to the weak oral bioavailability of RES, we hope to develop different administration methods in order to obtain good results in clinical treatment (Kotha et al., 2006).

There are six studies that used RES combined with cartilage tissue engineering scaffolds to treat OA. Kann et al. (2016) encapsulated RES and curcumin (CUR) in lipid-core nanocapsules and studied their interaction with the human primary chondrocytes. Due to the different solubilities of CUR and RES, the lower solubility accompanied faster release from the nanocapsules. The combination of the two can achieve the effect 
TABLE 1| The effect of flavonoids combined with carriers on OA cartilage repair.

\begin{tabular}{|c|c|c|c|c|c|c|c|c|}
\hline \multirow{2}{*}{$\begin{array}{l}\text { Research } \\
\text { (author } \\
\text { \& year) }\end{array}$} & \multirow[t]{2}{*}{ BDEs } & \multirow[t]{2}{*}{ Carrier } & \multicolumn{2}{|c|}{ Gene expression } & \multicolumn{2}{|c|}{ Cartilage repair effects } & \multirow[t]{2}{*}{ Other evaluations } & \multirow[t]{2}{*}{ Research conclusion } \\
\hline & & & Inhibition & Promote & $\begin{array}{c}\text { Imaging } \\
\text { evaluations }\end{array}$ & Tissue sections & & \\
\hline $\begin{array}{l}\text { Ouyang } \\
\text { et al. (2019) }\end{array}$ & Hes & $\begin{array}{l}\text { Gd2(CO3) } \\
\text { 3-PNs }\end{array}$ & $\begin{array}{l}\text { IL-6, TNF- } \alpha, \\
\text { NO, iNOS, } \\
\text { MMPs, Bax }\end{array}$ & $\begin{array}{l}\text { Col.Il, Bcl-2, } \\
\text { ACAN, } \\
\text { Sox9 }\end{array}$ & $\begin{array}{l}\text { Cartilage affinity of } \\
\text { synthesized NPS } \\
\text { based on MRI/IVIS }\end{array}$ & $\begin{array}{l}\text { Cartilage thickness, } \\
\text { caspase-3 } \\
\text { expression, and } \\
\text { OARSI score }\end{array}$ & $\begin{array}{l}\text { TLR2/NF-кB/Akt } \\
\text { signaling pathway }\end{array}$ & $\begin{array}{l}\text { HGdPDW could } \\
\text { effectively target cartilage } \\
\text { and protect chondrocytes } \\
\text { from apoptosis and } \\
\text { inflammation }\end{array}$ \\
\hline Mok (2018) & Que & MPIP & & & & OARSI score & $\begin{array}{l}\text { Llls (OA-related pain), } \\
\text { Krenn score (synovial } \\
\text { inflammation) }\end{array}$ & $\begin{array}{l}\text { Sustained delivery of Que } \\
(50 \mu \mathrm{g}) \text { could provide } \\
\text { symptom relief and also } \\
\text { delay the progression } \\
\text { of KOA }\end{array}$ \\
\hline $\begin{array}{l}\text { Kankala } \\
\text { et al. (2018) }\end{array}$ & $\mathrm{ICA}$ & SA/gel & & GAG & & & $\begin{array}{l}\text { The distribution of } \\
\text { chondrocytes on the } \\
\text { scaffold surface (by } \\
\text { CLSM) }\end{array}$ & $\begin{array}{l}\text { SA/gel composite scaffold } \\
\text { addition of ICA further } \\
\text { promoted cell proliferation } \\
\text { and differentiation }\end{array}$ \\
\hline $\begin{array}{l}\text { Li et al. } \\
\text { (2012) }\end{array}$ & ICA & $\mathrm{Col}-\mathrm{CH}$ & & $\begin{array}{l}\text { Col.l, Col.Il, } \\
\text { GAG, } \\
\text { ACAN, } \\
\text { Sox9 }\end{array}$ & $\begin{array}{l}\text { Restoration of } \\
\text { osteochondral } \\
\text { defects by direct } \\
\text { observation }\end{array}$ & $\begin{array}{l}\text { Restoration of the } \\
\text { osteochondral } \\
\text { defects and cartilage } \\
\text { thickness }\end{array}$ & $\begin{array}{l}\text { The morphology of } \\
\text { chondrocytes } \\
\text { encapsulated in } \\
\text { hydrogels (by CLSM) }\end{array}$ & $\begin{array}{l}\text { ICA can promote cartilage } \\
\text { repair and cartilage tissue } \\
\text { formation }\end{array}$ \\
\hline
\end{tabular}

CLSM, confocal laser scanning microscopic; EE, Encapsulation efficiency; ILLs, limb idleness index; IVIS, Interactive Video Information System; PNs, polydopamine nanoparticles; MPIP, methoxy-poly(ethylene glycol)-I-poly(alanine); $\mathrm{Col}-\mathrm{CH}$, collagen type I cell-hydrogel.

of rapid initial treatment (by RES) and prolonged treatment (by CUR). By virtue of its rapid release, RES can quickly clear ROS produced in OA rats induced by sodium nitroprusside (SNP) and reduce NO expression, thereby protecting the chondrocytes. Coradini et al. (2015) also studied the synergistic effects of RES and CUR using intraperitoneal injections instead of IA injections. RES and CUR were co-encapsulated in lipid core nano-capsules and intraperitoneally injected into Complete Freund's adjuvant (CFA)-induced arthritis rats. The results showed that co-encapsulated polyphenols were safe and nontoxic when injected in vivo and could significantly reduce foot swelling in arthritic rats $(p<0.05)$, with an amplitude of $37-55 \%$. In addition, co-encapsulated polyphenols alleviated cartilage damage by significantly reducing synovial membrane fibrosis and cartilage and bone loss $(p<0.05)$. Ming et al. (2018) used the microfluidic technique to select the optimum concentration of chondrocytes cultured by RES and then studied the reparative effects of RES and drug-loaded polylactic acid (PLA)/gelatin nano-scaffolds on cartilage defects. They reported that the best concentration of RES was $114.281 \mathrm{~mol} / \mathrm{L}$. Nanofiber scaffolds have good elasticity, mechanical strength, and compression recovery ability and can play a supporting role in the repair of cartilage defects. The results of animal experiments also showed that the PLA/gelatin 3D nano-scaffold could promote the repair of cartilage defects. RES (114.281 mol/L) loaded inside the scaffold could greatly promote the differentiation of chondrocytes and formation of cartilage, and maintain the normal structure of the new cartilage, with good cartilage defect reparative effects and improved OA treatment effects. Qin et al. (2020) prepared RESloaded silica aerogel (RSA) using the sol-gel method. In simulated gastric juice $(\mathrm{pH}=2.0)$ and a phosphate buffer $(\mathrm{pH}=7.4)$ at $37^{\circ} \mathrm{C}$, the release of RSA lasted for more than $6 \mathrm{~h}$, and the release amount reached 90 and 80\%, respectively. Preliminary in vitro toxicity tests showed that RSA had good biocompatibility and stability. Combined with the anti-inflammatory effects of RES, it shows great potential for treating OA. Sheu et al. (2013) prepared an oxidized HA (Oxi-HA)/RES hydrogel, which showed good biocompatibility. The Oxi-HA/Res hydrogel could upregulate the gene expression of COL2, aggrecan, and Sox9; promote ECM synthesis; downregulate the gene expression of IL-1B, MMP1, MMP3, and MMP13; and reduce inflammation and injury induced by lipopolysaccharides. The Oxi-HA/Res hydrogel may be a potential chondrocyte carrier for the treatment of cartilage defects. However, this study only carried out in vitro experiments, so further in vivo research is necessary to determine possible clinical application in the future. Kamel et al. (2019) prepared a mixed micellar system using poloxamer (P188:P407 = 2:1), then subjected it to in vitro and in vivo evaluation, and compared the curative effects of MM3, PLA-coated MM3, and drug suspension. PLA-coated MM3 had the best ability to eliminate knee edema, and MM3 had the best ability to remove TNF- $\alpha$. The addition of PLA coating can increase drug retention and reduce drug clearance from the synovial fluid. Histological studies have shown that articular and synovial structures can be restored through IA injection of drug-loaded micellar nano-systems. In addition, it can also reduce the symptoms of joint swelling in OA rats (Table 2).

\subsection{Curcumin}

CUR, a bioactive polyphenolic, is a natural BDEs which is mainly extracted from the rhizome of turmeric (Curcuma longa L.) (Feng et al., 2019b). CUR has significant antioxidant and free radical scavenging effects and is traditionally considered to possess antiinflammatory, anticancer, antioxidant, antiangiogenesis, and anti-radiation properties (Aggarwal et al., 2013; Tasneem et al., 2019; Hasanzadeh et al., 2020). 
Numerous previous studies have shown that CUR can inhibit chondrocyte apoptosis (Zhang et al., 2016; Henrotin et al., 2019). Its molecular mechanisms are not only associated with the inhibition of cell proliferation and metastasis but also associated with the downregulation of various factors such as TNF- $\alpha$, IL- $1 \beta$, and protease levels (Khayyal et al., 2018; Wang et al., 2019). Extensive research has revealed that CUR can exhibit anti-inflammatory effects on $\mathrm{OA}$ via suppressing the NF- $\kappa \mathrm{B}$ signaling pathway, IL-1 $\beta$, IL-6, IL-18, iNOS, prostaglandin E2 $\left(\mathrm{PGE}_{2}\right)$, and cyclooxygenase-2 (COX-2) (Chin, 2016; Zhang et al., 2016; Qiu et al., 2020). Chondrocyte apoptosis in OA is related to oxidative and endoplasmic reticulum (ER) stress (Feng et al., 2019b). Feng et al. (2019b) demonstrated that CUR protected rat chondrocytes from apoptosis by promoting SIRT1 expression and inhibiting ER stress and its related PERK-eIF2 $\alpha$-ATF4CHOP signaling pathway.

Yang et al. (2007) compared the routes of oral and intravenous administration of CUR and found that due to the very low oral bioavailability of CUR, its maximum plasma concentration $(500 \mathrm{mg} / \mathrm{kg})$ is much lower than that of intravenous injection $(10 \mathrm{mg} / \mathrm{kg})(0.06 \mathrm{vs} .0 .36 \mu \mathrm{g})$, and so a very high dose (>10 g/day) is required for oral administration to reach the plasma concentration recommended in the preclinical study (Belcaro et al., 2010; Gupte et al., 2019). A clinical study showed that CUR and low-dose ibuprofen had the same effect in reducing OA pain (Kuptniratsaikul et al., 2014; Gupte et al., 2019). A meta-analysis showed that the use of CUR as a dietary supplement was better than glucosamine (GA) and chondroitin in improving OA in the knee joints, hip joints, and hands in the short term (Liu et al., 2018b). Other studies have also shown that CUR can reduce OA pain and improve joint function while reducing the risk of adverse events (Panahi et al., 2014; Bannuru et al., 2018; Zeng et al., 2021) and can serve to decrease the use of NSAIDs which has more adverse effects (Grover and Samson, 2016; Wang et al., 2021a). At present, there are many methods, such as nanoparticles, liposomes, micelles, and phospholipid complexes, which can extend drug release time and increase permeability and resistance to clearance (Anand et al., 2007; Wang et al., 2019).

There are five studies that used CUR combined with a cartilage tissue engineering scaffold to treat OA. Kang et al. (2020) added CUR to the hydrophobic main chain of poly( $\beta$-amino ester) (PAE) to prepare anti-inflammatory polymeric prodrug of CUR (ACP) and found that amphiphilic ACP dissociated under acidic conditions. The potential of ACP micelles as a targeted therapeutic agent for inflammatory disease was investigated using an MIA-OA rat model due to the pathological characteristics of OA joints, such as low $\mathrm{pH}$ (6.6-7.1) and high ROS levels. In an acidic environment, the CUR release rate of ACP was very fast, $95 \%$ in 7 days, showing that it can play a role in accelerated drug treatment. ACP could significantly scavenge $\mathrm{H}_{2} \mathrm{O}_{2}$ and had no cytotoxicity when the concentration was lower than $100 \mu \mathrm{g} / \mathrm{ml}$. ACP could also significantly inhibit the levels of TNF- $\alpha$ and IL- $1 \beta$, with a stronger effect than that of free CUR. After treatment with ACP micelles, the articular surface of MIA-OA rats was smooth, the cartilage structure was intact, and the expression of proteoglycan, ACAN, and collagen protein was strong. The results showed that ACP micelles had strong anti-inflammatory and anti-arthritis properties. Yeh et al. (2015) used soybean phosphatidylcholines as a liposome formulation and compared the particle size, encapsulation efficiency, liposome stability, and cellular uptake of CUR/bisdemethoxycurcumin (BDMC)-loaded liposomes. The results showed that the encapsulation rates of CUR and BDMC in the liposomes were 69.5 and $71.4 \%$ respectively, and the particle size of the liposomes was stable after formation. Both liposomes inhibited macrophage inflammation and osteoclast differential activity. Compared with free drugs (such as CUR and BDMC), CUR-like liposomes (CUR-LIP) showed less cytotoxicity and a higher drug uptake rate. CUR-LIP can inhibit the proliferation of osteoclasts and maintain the differentiation function of osteoblasts by increasing the ratio of osteoprotectin (OPG)/ NF- $\kappa \mathrm{B}$ ligand receptor activator (RANKL), downregulating MMP3 and COX-2 induced by IL-1 $\beta$. Therefore, CUR liposomes may delay the progression of OA.

Crivelli et al. (2019) prepared silk fibroin nanoparticles (SFNs) using the desolvation method, then tested empty and drug-loaded [with CUR or celecoxib (CXB)] nanoparticles for their ROS scavenging activity, hemolysis, cytotoxicity, and antiinflammatory effects in an OA in vitro model. The results indicated that CUR-SFNs exhibited a synergistic antioxidant effect. SFNs encapsulation could reduce the cytotoxicity of free drugs. $\mathrm{CXB}$, a selective COX-2 inhibitor, is the first choice in the treatment of OA pain, but the long-term high-dosage use of $\mathrm{CXB}$ may cause serious cardiotoxicity and renal complications. On the contrary, CUR can reduce OA-related inflammation without obvious side effects. When free CUR was added to SFNs, its antioxidant activity increased from 80 to $90 \%$, while CBX showed no significant difference. Based on these findings, it can be speculated that the combination of SFNs and CUR has synergistic antioxidant effects. At high concentrations, the anti-inflammatory effects of SFNs/CUR $(400 \mu \mathrm{g} / \mathrm{ml})$ are greater than those of SFNs/CXB $(800 \mu \mathrm{g} / \mathrm{ml})$. Therefore, we believe that SFNs/CUR is more suitable for the treatment of OA than SFNs/ CXB. Of course, more in vivo and preclinical studies are needed to verify this view.

Wang et al. (2018) prepared HA/chitosan nanoparticles (cNP) for the delivery of CUR to investigate their effect on OA treatment. The results showed that the optimal drug loading of $\mathrm{HA} / \mathrm{cNP}$ for CUR was $38.44 \%$, which showed a good sustained release effect. CUR delivered by $\mathrm{HA} / \mathrm{cNP}$ inhibiting the inflammation and chondrocyte apoptosis of $\mathrm{OA}$ may be mediated by inhibiting the NF- $\mathrm{KB}$ pathway and expression of MMP1 and MMP13, and increasing the expression of COL2. Ratanavaraporn et al. (2017) prepared gelatin/silk fibroin microspheres loaded with CUR for use in the antiinflammatory treatment of MIA-OA rats. The results showed that the encapsulation efficiency of CUR by gelatin/silk fibroin (30/70) microspheres reached 59\%, the encapsulation amount of CUR microspheres was about $2 \mu \mathrm{g} / \mathrm{mg}$. CUR-coated gelatin/silk fibroin (30/70) microspheres reduced serum IL-6 levels and delayed the degeneration of joint and synovial tissue cells. These results indicate that the CUR-sustained release system 
TABLE 2 | The effect of RES combined with carriers on OA cartilage repair.

\begin{tabular}{|c|c|c|c|c|c|c|c|c|}
\hline \multirow{2}{*}{$\begin{array}{l}\text { Research } \\
\text { (author } \\
\text { \& year) }\end{array}$} & \multirow[t]{2}{*}{ BDEs } & \multirow[t]{2}{*}{ Carrier } & \multicolumn{2}{|c|}{ Gene expression } & \multicolumn{2}{|c|}{ Cartilage repair effects } & \multirow{2}{*}{$\begin{array}{c}\text { Other } \\
\text { evaluations }\end{array}$} & \multirow[t]{2}{*}{ Research conclusion } \\
\hline & & & Inhibition & Promote & $\begin{array}{c}\text { Imaging } \\
\text { evaluations }\end{array}$ & Tissue sections & & \\
\hline $\begin{array}{l}\text { Kann et al. } \\
(2016)\end{array}$ & $\begin{array}{l}\text { CUR } \\
\text { and } \\
\text { RES }\end{array}$ & PC-NPs & $\mathrm{NO}$ & & No mention & No mention & $\begin{array}{l}\text { Microscopy; cell } \\
\text { viability testing }\end{array}$ & $\begin{array}{l}\text { Polyphenols combined } \\
\text { with nanocapsules can } \\
\text { significantly reduce the } \\
\text { level of } \mathrm{NO} \text {, protect joint } \\
\text { cells, and prevent } \\
\text { apoptosis }\end{array}$ \\
\hline $\begin{array}{l}\text { Coradini } \\
\text { et al. (2015) }\end{array}$ & $\begin{array}{l}\text { CUR } \\
\text { and } \\
\text { RES }\end{array}$ & $\begin{array}{l}\text { Lipid-core } \\
\text { nanocapsules }\end{array}$ & & & No mention & $\begin{array}{l}\text { Significantly attenuation } \\
\text { of fibrosis in the synovial } \\
\text { membrane, cartilage, } \\
\text { and bone loss }\end{array}$ & & \\
\hline $\begin{array}{l}\text { Ming et al. } \\
\text { (2018) }\end{array}$ & RES & PLA-gel & & & $\begin{array}{l}\text { Significant articular } \\
\text { cartilage repair effect } \\
\text { were assessed by } \\
\text { general observation } \\
\text { and microCT }\end{array}$ & $\begin{array}{l}\text { A smooth and thick } \\
\text { cartilage surface and a } \\
\text { clear structure were } \\
\text { observed by } \\
\text { hematoxylin and eosin } \\
\text { staining, Safranin-O } \\
\text { Fast Green staining, } \\
\text { Alcian blue staining, and } \\
\text { toluene staining }\end{array}$ & & $\begin{array}{l}\text { PLA/gelatin 3D nano } \\
\text { scaffolds loaded with RES } \\
\text { can greatly promote the } \\
\text { formation of cartilage }\end{array}$ \\
\hline $\begin{array}{l}\text { Qin et al. } \\
(2020)\end{array}$ & RES & $\mathrm{SiA}$ & & & No mention & No mention & $\begin{array}{l}\text { Surface } \\
\text { morphology } \\
\text { analysis, FIIR } \\
\text { analysis, Raman } \\
\text { analysis }\end{array}$ & $\begin{array}{l}\text { RSA has biocompatibility } \\
\text { and stability; Combined } \\
\text { with the anti-inflammatory } \\
\text { effect of RES, it shows a } \\
\text { good potential in the } \\
\text { treatment of OA }\end{array}$ \\
\hline $\begin{array}{l}\text { Sheu et al. } \\
\text { (2013) }\end{array}$ & RES & $\mathrm{HA}$ & $\begin{array}{l}\text { IL-1 } \beta \text {, } \\
\text { MMPs, } \\
\text { Col.I }\end{array}$ & $\begin{array}{l}\text { Col.II, } \\
\text { ACAN, } \\
\text { Sox9 }\end{array}$ & No mention & No mention & $\begin{array}{l}\text { MTT, FTIR, and } \\
\text { TNBS assays }\end{array}$ & $\begin{array}{l}\text { Oxi-HA/RES hydrogel is } \\
\text { biocompatible with } \\
\text { chondrocytes, allowing } \\
\text { ECM synthesis and } \\
\text { reducing LPS-induced } \\
\text { inflammation and injury }\end{array}$ \\
\hline $\begin{array}{l}\text { Kamel et al. } \\
\text { (2019) }\end{array}$ & RES & PLA-P & TNF- $a$ & & & & & $\begin{array}{l}\text { RES-loaded mixed micellar } \\
\text { nanosystems reduce the } \\
\text { severity of cartilage injury } \\
\text { and synovitis }\end{array}$ \\
\hline
\end{tabular}

EE, Encapsulation efficiency; FTIR, Fourier transform infrared; PLA-P, PLA-coated poloxamer; HA, hyaluronic acid hydrogel; SiA, silica aerogel; PLA-gel, PLAVgelatine nano-scaffold; PCNPs, poly(e-caprolactone) nanocarriers; MTT, MTT assay; TNBS, trinitrobenzene sulfonate assay.

can be used for the local anti-inflammatory treatment of OA with reduced trauma.

\subsection{Epigallocatechin-3-Gallate}

Epigallocatechin-3-gallate (EGCG), a major extract of green tea [Camellia sinensis (L.) Kuntze], accounts for approximately 40-60\% of green tea polyphenols (Zheng et al., 2019). EGCG can inhibit the activation of p38 MAPK and c-Jun N-terminal kinase (JNK) (Singh et al., 2003) and significantly reduce the levels of TNF- $\alpha$ and MMP13 in human chondrocytes stimulated by AGEs (Rasheed et al., 2016). With both anti-inflammatory and antioxidant properties (Akhtar and Haqqi, 2011), EGCG inhibits COX-2 and $\mathrm{PGE}_{2}$ production via the upregulation of hsa-miR-199a-3p expression (Ahmed et al., 2002; Ownby et al., 2014; Jhang et al., 2016), inhibits IL-1 $\beta$-induced ADAMTS5 expression (Rasheed et al., 2016), and cartilage and proteoglycan degradation (Heinecke et al., 2010). Mice treated with EGCG showed OArelated pain relief (Leong et al., 2014), indicating that EGCG can not only delay the progression of OA but also relieve its symptoms.
Natarajan et al. (2015) verified the cartilage protective effects of EGCG through the IA injection of polyphenols, but it requires repeated injections, which is not popular in clinical medicine.

There are two animal studies that used EGCG combined with cartilage tissue engineering scaffolds. GA, an amino monosaccharide, is an important component of polyglucosamine which is found mainly in the cartilage matrix and synovial fluid. Its protective effects on cartilage are mainly inhibiting proteoglycan degradation, stimulating proteoglycan synthesis, inhibiting the activation of inflammatory cells, activating chondrocytes and synovial cells, and restoring joint function. Zheng et al. (2019) studied the effect mechanism of an EGCG-GA mixture and EGCG-GA-casein protein nanoparticles (EGCG-NPs) in OA rats. The results showed that EGCG, as a plant polyphenol, could significantly promote the effects of GA; nanoparticles (NPs) could significantly improve the stability of EGCG; and EGCG combined with NPs could inhibit TNF- $a$, IL$1 \beta$, IL-6, and IL-8 expression in OA rats, inhibit synovial hyperplasia and inflammatory cell infiltration, and effectively 
alleviate inflammation. It could also improve erythema and swelling around the joints in OA rats. The other study combined EGCG with HA and gelatin to create a composite hydrogel in order to explore the anti-inflammatory and cartilage protective effects of an EGCG-loaded composite hydrogel in the treatment of OA in vivo and in vitro (Jin et al., 2020b). After adding EGCG to the hydrogel, the cytotoxicity of EGCG was eliminated and it showed good biodegradability. Moreover, the expression of IL-1 $\beta$, TNF- $\alpha$, MMP13, and ADAMTS5 were significantly downregulated. Under in vitro experiment conditions, EGCG could promote the growth and differentiation of chondrocytes. After 4 weeks of injection into the joints of OA rats, no significant differences were observed in the surface or thickness of the cartilage between the injected rats and control rats. Therefore, we believe that EGCG combined with material scaffolds will be a promising tissue engineering strategy for repairing cartilage defects in OA.

\subsection{Honokiol}

Honokiol (HON) is a phenolic compound extracted from Magnolia officinalis Rehder \& E.H.Wilson (Kim et al., 2010). In vitro studies of macrophages and neutrophils showed that HON had antiinflammatory effects (Munroe et al., 2007). Other previous studies showed that HON may have a cartilage protective effect (Chen et al., 2014; Wu et al., 2017a). In the CIA-OA mice, the oral administration of magnolol and HON could block the production of IL-17, MMPs, RANKL, and NO in inflammatory joints and reduce serum TNF- $\alpha$ and IL- $1 \beta$ to inhibit inflammation, cartilage degeneration, and bone erosion (Kim et al., 2010) with no liver or kidney damage. However, its oral bioavailability is low, and only $1 \%$ can be absorbed. Moreover, $\mathrm{HON}$ can inhibit the levels of $\mathrm{PGE}_{2}$, NO, TGF- $\beta 1$, and IL- 6 , the protein expression of COX-2 and iNOS, and the phosphorylation of Akt, IkB- $\alpha$, and NF-kB, upregulated by IF-1 $\beta$ (Li et al., 2011; Chen et al., 2014). The results of Park et al. (2017) showed that HON could inhibit the osteoclastic effect mediated by RANKL. In addition, HON promotes the chondrogenesis of human umbilical cord MSCs and inhibits

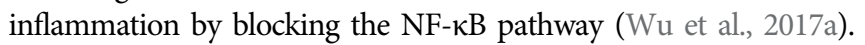
There is only one animal study that uses HON combined with a cartilage tissue engineering scaffold. Zhu et al. (2020) showed that HON significantly inhibited the release of pro-inflammatory cytokines TNF- $\alpha$, IL-1B, and IL-6 stimulated by lipopolysaccharide (LPS). In vivo, a scaffold containing HON was implanted into the cartilage defect area. After 8 weeks, the defect area was filled with COL2-positive cartilage tissue with an intact tide line structure, and the cartilage had become hard and smooth. Meanwhile, the ratio of the bone volume to tissue volume (BV: TV) was significantly increased. These results show that HON combined with a scaffold can promote the regeneration of hyaline cartilage and bone tissue in osteochondral defects (Table 3).

\section{ALKALOIDS}

\subsection{Brucine}

Brucine (BRU) is a major effective component of Strychnos nuxvomica L. (Wu et al., 2017b), with high toxicity (Liu et al., 2015a;
Lu et al., 2020). S. nux-vomica L. has a long history of clinical application in herbal medicine, especially in the treatment of RA and OA. BRU has anti-inflammatory and analgesic effects (Yin et al., 2003) and can significantly inhibit LPS-induced PGE $_{2}$ production (Liu et al., 2015a; Lu et al., 2020). BRU can effectively promote chondrocyte regeneration and repair cartilage damage caused by OA. Although BRU is highly effective in the treatment of OA, its potential use is severely limited due to its high toxicity; with its good lipid solubility, it can easily penetrate the blood-brain barrier and cause serious toxicity to the central nervous system if distributed in the brain (Gao et al., 2021). Its oral administration can also cause gastrointestinal irritation and systemic toxicity (Liu et al., 2015a; Lu et al., 2020). Until now, BRU has not been used clinically or studied in clinical trials. Therefore, new drug delivery systems are urgently needed to reduce the side effects (Liu et al., 2015a; Lu et al., 2020). There is only one animal study that used BRU combined with a cartilage tissue engineering scaffold. To determine the feasibility of IA injection, Chen et al. (2012) evaluated a BRU-loaded microsphere/thermally responsive hydrogel $(\mathrm{BMH})$ combination system in such aspects as drug release, pharmacodynamics, and biocompatibility. The results showed that the entrapment rate of this system was $98.60 \%$ $\mathrm{w} / \mathrm{w}$ with an average particle size of $0.9-4.5 \mu \mathrm{m}$. The sustained release cycle of $\mathrm{BMH}$ was 7 days. They established a rabbit OA model through the IA injection of collagenase and studied the therapeutic effects of this strategy on OA by IA injection. Histological assessment showed that $\mathrm{BMH}$ reduced the number of fibroblasts and improved synovial integrity during cartilage defect repair, and the pharmacodynamic results revealed that $\mathrm{BMH}$ could protect $\mathrm{OA}$ joints from degradation by suppressing TNF- $\alpha$ and IL- $1 \beta$ levels.

\subsection{Sinomenium}

Sinomenium (SIN) is a BDE extracted and purified from the plant Sinomenium acutum (Thunb.) Rehder \& E.H.Wilson (Chen et al., 2016b), which has anti-rheumatism, anti-inflammatory, and antipain effects (Wu et al., 2019a; Jiang et al., 2020). Clinically, SIN is widely used to treat patients with RA (Zhao et al., 2012). By activating the Nrf2/HO-1 signaling pathway and inhibiting NF$\kappa \mathrm{B}$ activity, SIN can reduce the protein levels of ADAMTS5 and MMPs in rats (Wu et al., 2019b), inhibit inflammation and ECM degradation, and play a role in cartilage protection ( $\mathrm{Wu}$ et al., 2019a). In addition, SIN downregulates iNOS, COX-2, NO, $\mathrm{PGE}_{2}$, TNF- $\alpha$, and IL- 6 induced by IL-1 $\beta$ (Wu et al., 2019a), suggesting that it protects chondrocytes by promoting autophagy and preventing cartilage degradation, thereby reducing the clinical symptoms of arthritis. However, few studies have evaluated the availability of SIN in the treatment of OA. There is only one animal study that used SIN combined with a cartilage tissue engineering scaffold. Chen et al. (2016b) evaluated the therapeutic effects of SIN coated with chitosan microspheres (CM-SIN) on OA by IA injection. Both in vivo and in vitro studies showed that SIN could partially induce autophagy to inhibit the degradation of the cartilage matrix induced by IL- $1 \beta$. SIN downregulates the mRNA expression of cartilage degradation markers MMP13 and ADAMTS5 and upregulates 
TABLE 3 | The effect of polyphenol active ingredients combined with carriers on OA cartilage repair.

\begin{tabular}{|c|c|c|c|c|c|c|c|c|}
\hline \multirow{2}{*}{$\begin{array}{l}\text { Research } \\
\text { (author } \\
\text { \& year) }\end{array}$} & \multirow[t]{2}{*}{ BDEs } & \multirow[t]{2}{*}{ Carrier } & \multicolumn{2}{|c|}{ Gene expression } & \multicolumn{2}{|c|}{ Cartilage repair effects } & \multirow{2}{*}{$\begin{array}{c}\text { Other } \\
\text { evaluations }\end{array}$} & \multirow[t]{2}{*}{ Research conclusion } \\
\hline & & & Inhibition & Promote & Imaging evaluations & Tissue sections & & \\
\hline Kang et al. (2020) & CUR & PEG & $\mathrm{IL}-1 \beta, \mathrm{TNF}-\alpha$ & $\begin{array}{l}\text { Col.II, } \\
\text { ACAN, } \\
\text { Sox9 }\end{array}$ & No mention & $\begin{array}{l}\text { Smooth surface with } \\
\text { structural integrity of } \\
\text { cartilage, along with } \\
\text { strong expression of } \\
\text { proteoglycan, ACAN, and } \\
\text { collagen, was observed } \\
\text { by H\&E, Masson's } \\
\text { trichrome, Safranin-O, } \\
\text { and ACAN staining }\end{array}$ & & $\begin{array}{l}\text { ACP micelles inhibit TNF- } \\
\alpha \text { and IL-1 } \beta \text {, significant } \\
\text { protection of joint } \\
\text { structure from arthritis }\end{array}$ \\
\hline Yeh et al. (2015) & CUR & $\begin{array}{l}\text { SPC- } \\
\text { liposome }\end{array}$ & $\begin{array}{l}\text { TRAP, } \\
\text { cathepsin K, } \\
\text { NO, MMPs, } \\
\text { COX-2 }\end{array}$ & $\begin{array}{l}\text { OPG/ } \\
\text { RANKL }\end{array}$ & No mention & No mention & $\begin{array}{l}\text { OPG/RANKL } \\
\text { signaling pathway }\end{array}$ & $\begin{array}{l}\text { CUR-loaded liposomes } \\
\text { can inhibit macrophage } \\
\text { inflammation and } \\
\text { osteoclast differentiation, } \\
\text { which may slow down } \\
\text { the progression of OA }\end{array}$ \\
\hline $\begin{array}{l}\text { Crivelli et al. } \\
\text { (2019) }\end{array}$ & CUR & SNPs & $\begin{array}{l}\text { IL-6, RANTES, } \\
\text { ROS, NO }\end{array}$ & & No mention & No mention & $\begin{array}{l}\text { FTIR, DSC, } \\
\text { TGA, SEM }\end{array}$ & $\begin{array}{l}\text { CUR and SFNs showed } \\
\text { synergistic antioxidant } \\
\text { effect }\end{array}$ \\
\hline Wang et al. (2019) & CUR & $\mathrm{HA} / \mathrm{cNP}$ & MMPs, NF-кB & Col.II & $\begin{array}{l}\text { Improved articular } \\
\text { surface injury in OA rats } \\
\text { by general observation } \\
\text { via a microscope }\end{array}$ & $\begin{array}{l}\text { The knee joint surface } \\
\text { was smooth, and the } \\
\text { cells were regularly } \\
\text { arranged in OA rats by } \\
\text { H\&E staining, toluidine } \\
\text { blue staining, Safranin-O } \\
\text { Fast Green staining }\end{array}$ & $\begin{array}{l}\text { UV assay; flow } \\
\text { cytometry; } \\
\text { western blot } \\
\text { analysis }\end{array}$ & $\begin{array}{l}\text { HA/cNP and CUR may } \\
\text { suppress inflammation } \\
\text { and chondrocyte } \\
\text { apoptosis in KOA via } \\
\text { repression of the NF-kB } \\
\text { pathway }\end{array}$ \\
\hline $\begin{array}{l}\text { Ratanavaraporn } \\
\text { et al. (2017) }\end{array}$ & CUR & Gel/SMs & IL-6 & & $\begin{array}{l}\text { Sign of OA was not } \\
\text { observed in the } \\
\text { treatment group via } \\
\text { X-ray }\end{array}$ & $\begin{array}{l}\text { Histologic and } \\
\text { histochemical grading of } \\
\text { articular joint and } \\
\text { synovial tissue change of } \\
\text { OA rats treated with } \\
\text { CUR-loaded gel/SMs } \\
\text { was significantly better } \\
\text { than in other groups }\end{array}$ & $\begin{array}{l}\text { Radiographic, } \\
\text { histological } \\
\text { examination }\end{array}$ & $\begin{array}{l}\text { CUR gel/SMs have } \\
\text { potential anti- } \\
\text { inflammatory effect on } \\
\text { OA joint in rats }\end{array}$ \\
\hline Jin. (2020) & EGCG & HA/gel & $\begin{array}{l}\text { IL-1 } \beta, \text { TNF- } \alpha \\
\text { ADAMTS5, } \\
\text { MMPs }\end{array}$ & $\begin{array}{l}\text { Col.II, } \\
\text { ACAN, } \\
\text { Sox9 }\end{array}$ & No mention & $\begin{array}{l}\text { In } 5 \% \text { HTG-E group, } \\
\text { cartilage surface and } \\
\text { thickness were } \\
\text { completely intact, } \\
\text { showing no signs of } \\
\text { wear and tear }\end{array}$ & & $\begin{array}{l}\text { HTG hydrogel can } \\
\text { promote the } \\
\text { accumulation of ECM, } \\
\text { and it has anti- } \\
\text { inflammatory and } \\
\text { cartilage protective ability } \\
\text { after loading EGCG }\end{array}$ \\
\hline $\begin{array}{l}\text { Zheng et al. } \\
\text { (2019) }\end{array}$ & EGCG & $\begin{array}{l}\text { EGC- } \\
\text { NPs }\end{array}$ & $\begin{array}{l}\text { IL-1 } \beta, \| \text { IL-6, } \\
\text { TNF- } \alpha\end{array}$ & & $\begin{array}{l}\text { The therapeutic effect of } \\
\text { the EGC-NPs was } \\
\text { significantly better than } \\
\text { that of the EGCG-GA } \\
\text { mixture and } \\
\text { comparable to the } \\
\text { antiarthritic effect of } \\
\text { celecoxib by a } \\
\text { radiographic evaluation } \\
\text { and scoring system }\end{array}$ & $\begin{array}{l}\text { Combined with EGCG, } \\
\text { GA can effectively } \\
\text { promote its antiarthritic } \\
\text { effects }\end{array}$ & & $\begin{array}{l}\text { The anti-inflammatory } \\
\text { effect of EGC-NPs was } \\
\text { significantly higher than } \\
\text { that of the EGCG-GA } \\
\text { mixture }\end{array}$ \\
\hline Zhu et al. (2020) & $\mathrm{HON}$ & $\begin{array}{l}\text { ECM/ } \\
\text { PGDH }\end{array}$ & $\begin{array}{l}\text { IL-1 } \beta, \text { IL-6, } \\
\text { TNF- } \alpha\end{array}$ & $\begin{array}{l}\text { Col.I, } \\
\text { Col.II, BV: } \\
\text { TV, Tb.Th }\end{array}$ & $\begin{array}{l}\text { In the group in which } \\
\text { the defect was repaired } \\
\text { with PEGDAVEM/ } \\
\text { HON scaffold, the } \\
\text { surfaces of the defect } \\
\text { were smooth and the } \\
\text { defect region displayed } \\
\text { an intact tideline } \\
\text { structure via micro-CT }\end{array}$ & $\begin{array}{l}\text { The defects in the } \\
\text { PEGDA/ECM/HON } \\
\text { group were mostly filled } \\
\text { with cartilage tissue } \\
\text { positive for COL2, } \\
\text { indicating regeneration } \\
\text { of hyaline cartilage-like } \\
\text { tissue }\end{array}$ & & $\begin{array}{l}\text { Scaffolds combined with } \\
\text { HON promoted the } \\
\text { regeneration of hyaline } \\
\text { cartilage and } \\
\text { subchondral bone }\end{array}$ \\
\hline
\end{tabular}

EE, Encapsulation efficiency; CFA, Complete Freund's adjuvant; H\&E, hematoxylin and eosin; SNP, sodium nitroprusside; FTIR, Fourier transform infrared; Tb. Th, trabecular thickness; HAVCNP, HA/chitosan nanoparticles; gel/SMs, gelatin/Thai silk fibroin microspheres; HA/gel, HA/gelatin hybrid hydrogel; ECM/PGDH, 3D-printed ECM/polyethylene glycol diacrylate hydrogel; SNPS, silk fibroin nanoparticles; PEG, poly(ethylene glycol); HA, hyaluronic acid hydrogel; PC-NPS, poly(s-caprolactone) nanocarriers; UV, ultraviolet; DSC, Differential scanning calorimetry; TGAVDSC 1, Simultaneous thermogravimetric analysis; SEM, scanning electron microscopy; HTG, HAVgelatin; SPC, Soybean phosphatidylcholine; TRAP, tartrate-resistant acid phosphatase; HTG-E, EGCG-loaded HAVgelatin; EGC-NPS, EGCG-GA-Casein Nanoparticles. 
the expression of ECM components COL2A1 and ACAN. After the IA injection of CM-SIN for 4 and 8 weeks, the OARSI score of OA mice was significantly reduced $(p<0.01)$, cartilage degeneration was improved, and OA progression was delayed.

\subsection{Berberine}

Berberine (BBR) is an active component isolated from Coptis chinensis Franch.("Huanglian" in Chinese) (Neag et al., 2018). BBR has obvious immunosuppressive, anticancer (Mishra et al., 2019), and anti-inflammatory effects (Hu et al., 2011; Zhou et al., 2015a; Belwal et al., 2020). It has been shown that BBR can activate the Wnt/ $\beta$-catenin signaling pathway in OA rats (Zhou et al., 2016a). Wnt signaling molecules play an important role in the process of osteogenesis (Wong et al., 2020), so it can be speculated that BBR can upregulate the Wnt signaling pathway and promote the reconstruction of the subchondral bone. BBR has also been reported to enhance autophagy levels in chondrocytes (Chen et al., 2018). BBR significantly inhibits IL$1 \beta$-induced inflammation by inhibiting the NF- $\mathrm{BB}$ signaling pathway in human OA chondrocytes (Zhou et al., 2016b; Lu et al., 2019) and significantly inhibits the IL- $1 \beta$-induced expression of MMP3, MMP13 (Moon et al., 2011; Belwal et al., 2020), iNOS, and COX-2, and the production of NO and E2. In addition, BBR inhibits apoptosis and promotes the proliferation of SNP-stimulated chondrocytes in rats and OA rats (Zhou et al., 2015b; Zhou et al., 2017). BBR also promotes articular chondrocyte survival and stroma formation by activating Akt signaling (Zhao et al., 2014; Liu et al., 2015b). However, BBR has poor water solubility, low bioavailability, and a short biological half-life, so it is necessary to design a continuous delivery system to improve its utilization.

There are three animal studies that used BBR combined with cartilage tissue engineering scaffolds. Chen et al. (2018) investigated the effects of a combined $\mathrm{BBR}$ and sodium hyaluronate/SA (HA/SA) scaffold on cartilage repair. In vitro, the scaffold sizes ranged from 100 to $200 \mu \mathrm{m}$, and all BBR was released within $72 \mathrm{~h}$. HA/SA-IPN scaffolds combined with BBR can activate the Wnt/ $\beta$-catenin signaling pathway to promote the osteogenesis differentiation of BMSCs and increase the bone volume to tissue volume ratio (BV/TV). Meanwhile, the cartilage defect surface of the BBR and scaffold group was smooth and filled with thicker hyaline cartilage-like tissue. In vivo, BBR significantly increased the level of autophagy marker LC3, downregulated MMP13 and ADAMTS5, and upregulated COL2A1 and ACAN. These results suggest that BBR inhibits the degradation of the cartilage matrix by enhancing autophagy and promoting cartilage regeneration. We believe that this system can regenerate not only cartilage but also subchondral bone simultaneously, which is a promising strategy for osteochondral defect repair. Zhou et al. (2015a) successfully synthesized $\mathrm{CNs}$ for the sustained release of BBR using the ionic cross-linking method and established an OA rat model by ACLT combined with medial meniscal resection (ACLT + $\mathrm{MMx}$ ). In vitro, the CNs could continuously release BBR, with good stability, uniform morphology and structure, good particle size and appropriate Zeta potential, and encapsulate a large amount of BBR. In the ACLT + MMx rat model, BBR significantly downregulated the mRNA expression of caspase- 3 and Bax and upregulated the mRNA expression of Bcl-2. The Mankin score was used for histopathological scoring, and the results showed that the BBR-CNs group was significantly better than the model group in structural changes, chondrocyte changes, tide mark, and safranin staining $(p<0.001)$, and the cartilage damage of $\mathrm{OA}$ rats was reversed. These results suggest that the IA administration of BBR-CNs may be an effective treatment for OA. Zhou et al. (2017) successfully synthesized a new type of BBR-loaded chitosan microspheres (CMs) with an encapsulation efficiency of $100.8 \pm 2.7 \mathrm{mg} / \mathrm{g}$. CMs loaded with BBR significantly inhibited the protein expression levels of caspase-3, disintegrin, ADAMTS5, and MMP13 induced by SNP, which confirmed its antiapoptotic activity. However, they did not conduct further animal model tests to verify the system's effectiveness in vivo.

\subsection{Colchicine}

Colchicine (CLC) is a water-soluble alkaloid extracted from Colchicum autumnale L. (Mohamed et al., 2020) and the first therapy of choice in gout treatment (Letter, 1974). Due to its antiinflammatory and anti-fibrosis properties (Leung et al., 2018), CLC is used not only in the treatment of arthritis but also as a remedy to treat numerous skin conditions (Sullivan et al., 1998), Familial Mediterranean fever (Knieper et al., 2017), Behcet's disease (Nava et al., 2014), cirrhosis (Kershenobich et al., 1988; Gong and Gluud, 2004; Rambaldi and Gluud, 2005), and certain carcinomas (Mohamed et al., 2020). Clinical studies have shown that CLC can significantly improve symptoms in KOA patients (Das et al., 2002). However, a study by Leung et al. (2018) showed that CLC $(0.5 \mathrm{mg}$, twice daily, orally, 16 weeks) did not reduce KOA symptoms but reduced the inflammatory and high bone turnover biomarkers associated with OA severity and risk of progression. The oral administration of CLC has certain limitations due to its extensive first-pass effects, poor bioavailability, and severe gastrointestinal side effects (Abdulbaqi et al., 2018). At the same time, the intravenous administration of CLC can cause serious or even fatal effects such as cell loss, tissue necrosis, and intravascular coagulation transmission (Evans et al., 1996; Abdulbaqi et al., 2018), and its intravenous administration is prohibited. In addition, the high water and poor skin permeability of CLC pose challenges for its transdermal delivery (Mohamed et al., 2020). Most importantly, the chronic and progressive nature of $\mathrm{OA}$ requires frequent administration. Thus, in order to ensure better safety and effectiveness, it is urgent to find an alternative administration route for CLC (Marwah et al., 2016).

There is only one animal study that used CLC combined with a cartilage tissue engineering scaffold. Mohamed et al. (2020) developed novel CLC transdermal delivery systems to conquer such obstacles. Compared with the drug suspension liquid, the patch increased the drug flux and penetration level for more than $24 \mathrm{~h}$. The therapeutic effects of the CLC patch on the MIA-OA rat model showed that CLC improved exercise ability, increased the blood glutathione level, and significantly reduced the malondialdehyde, NO, TNF- $\alpha$, and COX- 2 levels. The histopathological evaluation of the rats' knee joints showed 
that rats treated with CLC patches showed similar near-normal structures, regular smooth cartilage surfaces, and dense bone joint lumens when compared to those of the control group. These results show that the CLC preparation had good protective and therapeutic effects on bone tissue damage caused by MIA-OA (Table 4).

\section{OTHERS}

\subsection{Ginger Extract}

Ginger is the rhizome of Zingiber officinale Roscoe, and its extract can inhibit the mitochondrial pathway of cell apoptosis (Hosseinzadeh et al., 2017). When inflammation causes apoptosis of articular chondrocytes in $\mathrm{OA}$, the value of apoptosis mitochondrial pathway marker $\mathrm{Bax} / \mathrm{Bcl}-2$ increases (Lee et al., 2004). Numerous studies have shown that the treatment of OA with ginger extract (GINE) is effective and safe (Bliddal et al., 2000; Leach and Kumar, 2008; Bartels et al., 2015; Rondanelli et al., 2020). Experimental studies found that $0.01,0.5,1,5,10,25,50$, and $100 \mu \mathrm{g} / \mathrm{ml}$ of GINE was nontoxic to C28I 2 chondrocytes, and 5 and $25 \mu \mathrm{g} / \mathrm{ml}$ of GINE can reduce the ROS production, upregulate the expression of antioxidant enzymes GPx-1, GPx-3, GPx-4, and SOD1, reduce the value of $\mathrm{Bax} / \mathrm{Bcl}-2$, inhibit the activation of caspase-3, inhibit the apoptosis mitochondrial pathway signal stimulated by IL- $1 \beta$, and reduce apoptosis of human C28I2 chondrocytes (Hosseinzadeh et al., 2017; Li et al., 2020). However, the oral administration of GINE can cause gastrointestinal reactions, poor absorption, rapid metabolism, and the elimination of the active compound, and GINE itself has low bioavailability. Therefore, several studies have suggested that its transdermal administration is safer than oral (Amorndoljai et al., 2015).

There is only one clinical study that used GINE combined with a cartilage tissue engineering carrier. Amorndoljai et al. (2015) prepared a topical liniment by combining GINE and nanostructured lipid carrier (NLC). About $60 \mathrm{KOA}$ patients (aged 50-75 years) were included afterward and applied this liniment three times per day. After 12 weeks of treatment, the GINE nanoparticles significantly improved the patients' overall assessment, knee pain, symptoms, daily activity, physical activity, and quality of life, and their Knee Injury and Osteoarthritis Outcome Score (KOOS), Index of Severity for Osteoarthritis (ISOA), and Patient's Global Assessment (PGA) results were statistically significant $(p<0.05)$. There were no safety problems or adverse events.

\subsection{Cordycepin}

Cordycepin ( $3^{\prime}$-deoxyadenosine) (COR) is a nucleoside analog isolated from Cordyceps militaris (L.) Fr., which occupies a notable place in traditional medicine. In recent years, many studies have verified that COR has anticancer, antiangiogenesis, antiaging, and other pharmacological effects (Khan and Tania, 2020). It has also been found that COR can induce cell apoptosis and autophagy. Moreover, a recent study has shown that COR significantly inhibited the production of $\mathrm{PGE}_{2}$ and $\mathrm{NO}$ and decreased the production of MMP13, IL-6,
iNOS, and COX-2 in OA chondrocytes induced by IL-1 $\beta$ (Hu et al., 2014). These clues suggest that COR inhibits TGF- $\beta$ activity, induces autophagy, and prevents cartilage degradation to protect the chondrocytes (Ying et al., 2014; Ashraf et al., 2019; Tao et al., 2020). It is suggested that COR may be a potential candidate drug for the prevention of OA. However, few studies have evaluated its efficacy in the treatment of OA (Xia et al., 2017).

There is only one animal study that used COR combined with a cartilage tissue engineering carrier. Xia et al. (2017) investigated the synergistic effects of hydrogel and COR on the promotion of chondrocyte autophagy, both in vivo and in vitro. All of the CMs-encapsulated COR (CM-COR) was released in phosphate-buffered saline within $72 \mathrm{~h}$. COR decreased the mRNA expression of MMP13 and ADAMTS5 and increased the mRNA expression of COL2A1 and ACAN. In addition, COR significantly increased the expression of LC3-positive chondrocytes in cartilage tissue, suggesting that COR can activate autophagy to prevent IL- $1 \beta$-induced cartilage degradation. After receiving CM-COR + hydrogel, cartilage degeneration decreased, the OARSI score reached $3.4 \pm 0.3$, and the progression of OA was delayed to the greatest extent.

\subsection{Tetramethylpyrazine/Ligustrazine}

Tetramethylpyrazine (TMP), also called ligustrazine (LIG), is a botanical extract component separated from Conioselinum anthriscoides "Chuanxiong," which has strong antiinflammatory (Wei et al., 2016; Chen et al., 2017) and cartilage protection properties (Ju et al., 2010). In recent years, TMP has proven to be an effective candidate for the treatment of OA (Zhang et al., 2018) as it can reduce IL- $1 \beta$-induced GAG degradation, MMP3 mRNA expression, and IL-1-induced cartilage and chondrocyte degeneration, thereby improving chondrocyte activity and inhibiting their apoptosis. ROS and the apoptotic mitochondrial pathways influence articular cartilage degeneration in OA (Kim and Blanco, 2007; Musumeci et al., 2015). Furthermore, TMP scavenges cytotoxic ROS to maintain the mitochondrial membrane potential and downregulate caspase- 3 activity (Ju et al., 2010). However, TMP is quickly erased from the articular cavity after IA injection, so multiple injections are required to maintain the curative effect, which may lead to the inflammation and infection of local tissues. Reducing the number of injections is the key to increasing patient compliance (Zhang et al., 2018).

There are three animal studies that used TMP/LIG combined with cartilage tissue engineering carriers. Zhang et al. (2018) evaluated the curative effects of TMP microspheres on joint swelling and histological analysis in a papain-induced OA rat model. The drug loading of freeze-dried microspheres $(81.36 \pm$ $1.15 \%)$ was greater than that of vacuum-dried microspheres $(8.22 \pm 0.19 \%)$. The freeze-dried microspheres had a particle size of about $10 \mu \mathrm{m}$ and excellent sustained release properties, effectively able to extend the release time of the drug in the articular cavity to 30 days (4.7 times more than the TMP solution). TMP microspheres were also superior to the TMP solution in improving the range of motion and swelling of OA 
TABLE 4 | The effect of alkaloid active ingredients combined with carriers on OA cartilage repair.

\begin{tabular}{|c|c|c|c|c|c|c|c|c|}
\hline \multirow{2}{*}{$\begin{array}{l}\text { Research } \\
\text { (author } \\
\text { \& year) }\end{array}$} & \multirow[t]{2}{*}{ BDEs } & \multirow[t]{2}{*}{ Carrier } & \multicolumn{2}{|c|}{ Gene expression } & \multicolumn{2}{|c|}{ Cartilage repair effects } & \multirow{2}{*}{$\begin{array}{c}\text { Other } \\
\text { evaluations }\end{array}$} & \multirow[t]{2}{*}{ Research conclusion } \\
\hline & & & Inhibition & Promote & Imaging evaluations & Tissue sections & & \\
\hline $\begin{array}{l}\text { Chen et al. } \\
\text { (2012) }\end{array}$ & $\mathrm{BRU}$ & $\mathrm{MH}$ & $\mathrm{IL}-1 \beta, \mathrm{TNF}-\alpha$ & & $\begin{array}{l}\text { The severity of OA was } \\
\text { milder in the BMH group } \\
\text { than in the saline group } \\
\text { via gross pathological } \\
\text { observation }\end{array}$ & $\begin{array}{l}\text { The number of } \\
\text { fibroblasts was } \\
\text { significantly decreased } \\
\text { and the integrity of } \\
\text { synovium was } \\
\text { improved in the BS and } \\
\text { BMH groups than in the } \\
\text { saline group }\end{array}$ & $\begin{array}{l}\text { X-ray (release } \\
\text { profiles of BRU), } \\
\text { SEM, FX } \\
\text { imaging }\end{array}$ & $\begin{array}{l}\text { BRU-loaded } \mathrm{MH} \text { can inhibit } \\
\text { the expression of TNF- } \alpha \text { and } \\
\mathrm{IL}-1 \beta \text { to protect OA joint }\end{array}$ \\
\hline Chen (2015) & SIN & $\begin{array}{l}\text { CM/ } \\
\text { GelMA }\end{array}$ & $\begin{array}{l}\text { IL-1 } \beta \\
\text { ADAMTS5 }\end{array}$ & $\begin{array}{l}\text { Col.Il, } \\
\text { ACAN, LC3 }\end{array}$ & No mention & $\begin{array}{l}\text { The combination of } \\
\text { CM-SIN and GeIMA } \\
\text { hydrogel retarded the } \\
\text { progression of } \\
\text { surgically induced OA, } \\
\text { while each of these } \\
\text { components alone also } \\
\text { had a mild beneficial } \\
\text { effect according to the } \\
\text { OARSI score }\end{array}$ & SEM, RT-PCR & $\begin{array}{l}\text { SIN combined with scaffolds } \\
\text { can improve the progression } \\
\text { of surgically induced OA by } \\
\text { promoting autophagy }\end{array}$ \\
\hline $\begin{array}{l}\text { Mohamed } \\
\text { et al. (2020) }\end{array}$ & CLC & MSN & $\begin{array}{l}\text { IL-1 } \beta, \mathrm{NO} \\
\mathrm{COX}-2\end{array}$ & & No mention & $\begin{array}{l}\text { the rats group treated } \\
\text { with formula } 2 \text { showed } \\
\text { nearly normal } \\
\text { architecture like normal } \\
\text { control with a regular } \\
\text { smooth surface }\end{array}$ & $\begin{array}{l}\text { TEM, FTIR, } \\
\text { FE-SEM }\end{array}$ & $\begin{array}{l}\mathrm{COL}-\mathrm{MSN} / \text { hydrogel patch is } \\
\text { an effective, safe, and } \\
\text { convenient treatment for } \mathrm{OA}\end{array}$ \\
\hline $\begin{array}{l}\text { Chen et al. } \\
\text { (2018) }\end{array}$ & $\mathrm{BBR}$ & HA/SA & $\begin{array}{l}\text { ADAMTS5, } \\
\text { MMPs }\end{array}$ & $\begin{array}{l}\text { Col.Il, } \\
\text { ACAN, BV/ } \\
\text { TV, Wnt/ } \beta- \\
\text { catenin, LC3 }\end{array}$ & $\begin{array}{l}\text { The defect surface } \\
\text { became smooth in the } \\
\text { group of scaffold + BER, } \\
\text { by general observation, } \\
\text { and the results of the } \\
\text { micro-CT scans } \\
\text { demonstrated that much } \\
\text { more calcified tissue was } \\
\text { produced at } 4 \text { and } \\
8 \text { weeks post-surgery in } \\
\text { the defect regions } \\
\text { implanted with the } \\
\text { scaffold in combination } \\
\text { with BER than in those } \\
\text { implanted with the } \\
\text { scaffold without BER }\end{array}$ & $\begin{array}{l}\text { The OA mice treated } \\
\text { with BER showed } \\
\text { better cartilage } \\
\text { surfaces with cracks } \\
\text { and a markedly lower } \\
\text { OARSI score } \\
\text { compared to that of the } \\
\text { untreated OA mice }\end{array}$ & & $\begin{array}{l}\text { BER combined with HASA } \\
\text { can activate Wnt signaling } \\
\text { pathway, repair subchondral } \\
\text { bone, and promote } \\
\text { autophagy to protect the } \\
\text { cartilage }\end{array}$ \\
\hline $\begin{array}{l}\text { Zhou et al. } \\
\text { (2015a) }\end{array}$ & $\mathrm{BBR}$ & CNs & $\begin{array}{l}\text { Bax, } \\
\text { caspase-3 }\end{array}$ & $\mathrm{Bcl}-2$ & $\begin{array}{l}\text { The cartilage damage in } \\
\text { the OA + BBR-loaded } \\
\text { CNs group was } \\
\text { significantly reversed by } \\
\text { general observation }\end{array}$ & $\begin{array}{l}\text { Mankin scores revealed } \\
\text { that BBR-loaded CNs } \\
\text { treatment antagonized } \\
\text { a stronger effect on the } \\
\text { amelioration of cartilage } \\
\text { damage }\end{array}$ & & $\begin{array}{l}\text { BBR-loaded CNs further } \\
\text { showed anti-apoptosis } \\
\text { activity in the treatment of OA }\end{array}$ \\
\hline $\begin{array}{l}\text { Zhou et al. } \\
\text { (2017) }\end{array}$ & $\mathrm{BBR}$ & $\mathrm{CMs}$ & $\begin{array}{l}\text { ADAMTS5, } \\
\text { MMPs, } \\
\text { caspase-3 }\end{array}$ & & No mention & No mention & & $\begin{array}{l}\text { BBR-CMs showed } \\
\text { enhanced anti-apoptotic and } \\
\text { chondroprotective effects on } \\
\text { the treatment of OA }\end{array}$ \\
\hline
\end{tabular}

SEM, scanning electron microscopy; LC3, 1AV1B-light chain 3; RT-PCR, real-time polymerase chain reaction; TEM, transmission electron microscopy; BMSCs, bone marrow-derived MSCs; MMx, medial menisci resection; MH, chitosan-glycerol-borax microsphere/thermally responsive hydrogel; CM/GelMA, chitosan microspheres and photo-cross-linked gelatin methacryloyl hydrogel; MSN, mesoporous silica nanoparticles/hydrogel; HA/SA, hyaluronate and SA scaffold; CNs, chitosan nanoparticles; CMs, chitosan microspheres; BS, brucine solution; BER, berberine.

joints and promoting the repair of cartilage defects. TMP microspheres showed powerful advantages in reducing drug dose, limiting injection times, and improving efficacy. Two other similar studies showed that a combination of nanoparticles and LIG could improve bioavailability and targeting, and effectively reduce synovial MMP levels and NF$\kappa B$ expression upstream of the NF- $\kappa B$ signaling pathway, thereby alleviating KOA and reducing adverse reactions (Ji et al., 2021). The combination of TMP and nanoparticles can lengthen the retention in the articular cavity, enhance the concentration of 
TMP, and improve the anti-inflammatory effects while avoiding systemic toxicity ( $\mathrm{Li}$ et al., 2021).

\subsection{Andrographolide}

Andrographolide (AG) is a major plant extract of Andrographis paniculata (Burm. f.) Nees, which is known for its antioxidant and anti-inflammatory effects (Burgos et al., 2020; Kulsirirat et al., 2021a). A double-blind, randomized, placebo-controlled study also found AG (300 and $600 \mathrm{mg} /$ day) to be effective and safe in relieving pain in patients with mild to moderate KOA (Hancke et al., 2019). The pharmacological mechanism may be as follows: AG suppresses synovial inflammation via the regulation of TNF- $\alpha$ receptor 2 (TNF-R2) trafficking (Wang et al., 2021b); activates the Keap1Nrf2-ARE pathway, and increases cell proliferation inhibited by $\mathrm{H}_{2} \mathrm{O}_{2}$ and antioxidant enzyme activity to alleviate the oxidative stress damage of chondrocytes (Li et al., 2018); specifically, AG can promote the osteogenesis and chondrogenesis of human suprapatellar fat pad-derived MSCs (Kulsirirat et al., 2021b), and it inhibits the activation of NF- $\mathrm{KB}$ and MMP13 expression stimulated by IL-1 $\beta$ in the chondrocytes (Ding et al., 2013; Chen et al., 2020b). However, the low water solubility and high lipid solubility of AG reduce its bioavailability and thus limit its oral absorption (He et al., 2021). Therefore, a continuous delivery system is needed to maximize the pharmacological benefits of AG.

There are two animal studies that used AG combined with a cartilage tissue engineering carrier. He et al. (2021) used an OA rat model to verify the anti-inflammatory and cartilage protection ability of AG combined with mesoporous silica nanoparticles (AG-MSNs). The results showed drug encapsulation efficiency of $43.39 \pm 0.33 \%$ and drug loading capacity of $22.38 \pm 0.71 \%$, while at $\mathrm{pH}=5.6, \mathrm{AG}$ could be released continuously for $48 \mathrm{~h}$ with an accumulated release rate of about $80 \%$. AG-MSNs prevented the IL-1 $\beta$-mediated upregulation of MMP3 and MMP13 (64.66 and 67.33\%). AG and AG-MSNs showed remarkable antiinflammatory properties, decreasing the damage to chondrocytes stimulated by IL- $1 \beta$. It is noteworthy that $\mathrm{pH}$ responsive polyacrylic acid (PAA)-loaded Ag-MSNs was superior to AG-MSNs in the OARSI score, cartilage protection effects, and anti-inflammatory effects. In addition, Kulsirirat et al. (2021a) showed that combined use of a gelatin-based hydrogel with AG-NPs significantly extended the duration for more than 1 month. Unfortunately, only the in vivo sustained release time of the drug delivery system was reported, and no analysis of cartilage defect repair was performed.

\subsection{Celastrol}

Celastrol (CSL) is a pentacyclic triterpenoid extracted from Tripterygium wilfordii Hook. f., which has been widely used to treat RA (Song et al., 2019), systemic lupus erythematosus (Xinqiang et al., 2020), and cancer (Wang et al., 2007). Previous studies have shown that CSL can block IL- $1 \beta$ and TNF secretion in $\mathrm{OA}$ animals and eliminate the infiltration and proliferation of immune cells, thereby preventing cartilage and bone defects (Liu et al., 2020b). In different types of cells, CSL can inhibit IKK complex phosphorylation I $\kappa \mathrm{B} a$, one of the key steps of NF- $\kappa \mathrm{B}$ activation (Jin et al., 2020a). The NF- $\kappa B$ signaling pathway is a typical signaling pathway involved in the development of $\mathrm{OA}$ pathobiology. The NF- $\kappa$ B transcription factor can induce cartilage degradation and promote the secretion of a variety of degradation enzymes such as MMPs and ADAMTS, which play a key role in the degradation of ECM structural proteins (Feng et al., 2020). However, the clinical application of CSL is limited due to its systemic toxicity and poor bioavailability caused by its low water solubility $\left(13.25 \pm 0.83 \mu \mathrm{g} / \mathrm{ml}\right.$ at $37^{\circ} \mathrm{C}$ ) (Wang et al., 2007). There is only one animal study that used CSL combined with a cartilage tissue engineering carrier. Jin et al. (2020a) verified an antiinflammatory therapy against KOA through the IA injection of hollow mesoporous silica NPs loaded with CSL. the NPs largely improved the dissolution rate of CSL to $73.99 \%$ (from 12.96\%). When $\mathrm{pH}=6$, the release of CSL was triggered, exerting an antiinflammatory effect, cartilage protective effect through the prevention of COL2 degradation, and downregulation of MMP3 and MMP13 expression.

\subsection{1-Keto- $\beta$-Boswellic Acid}

Numerous studies on the pharmacological properties of Boswellia serrata Roxb. gum-resin extract 11-keto- $\beta$-boswellic acid (KBA) have shown its therapeutic effects on inflammatory diseases such as OA, RA, inflammatory bowel disease, and cancer (Bairwa and Jachak, 2016; Efferth and Oesch, 2020). KBA downregulates proinflammatory cytokines such as TNF- $\alpha$, IL-1, IL-2, IL-4, IL-6, and IFN- $\gamma$ and increases the phagocytosis of macrophages. The inhibitory effect of $\mathrm{KBA}$ on 5-lipoxygenase could lead to a decrease in leukotriene production. Various chronic inflammatory diseases are associated with increased leukotriene activity (Ammon, 2010; Efferth and Oesch, 2020). However, the pharmacological activity of KBA is limited by its low oral bioavailability, low water solubility and high Phase I metabolism (Bairwa and Jachak, 2016). There is only one animal study that used KBA combined with a cartilage tissue engineering carrier. Bairwa and Jachak (2016) developed an oral preparation of KBA nanoparticles (KBA-NPs) to improve its bioavailability and anti-inflammatory activity. The particle size was $152.6 \mathrm{~nm}$, the polydispersity index was 0.194 , the encapsulation rate was $79.7 \%$, and the cumulative release of $\mathrm{KBA}$ was $61.5 \%$ at $72 \mathrm{~h}$. Compared with KBA suspension (34.9\%), the inhibition rate of KBA-NPs on rat foot swelling at $5 \mathrm{~h}$ was $60.8 \%$, and the bioavailability and anti-inflammatory activity of KBA-NPs were increased by seven times and 1.7 times, respectively. The increased anti-inflammatory activity of KBA-NPs may be due to its increased bioavailability. However, the study did not report the effects of the administration system on cartilage defect repair (Table 5).

\section{A SUMMARY OF THE APPLICATION OF BOTANICAL DRUG EXTRACTS AND CARRIERS IN THE REPAIR OF CARTILAGE DEFECTS}

\subsection{Preparation of Carriers}

Scaffolding is of great significance in cartilage tissue engineering. It is worth noting that electrostatic spinning technology and $3 \mathrm{D}$ 
printing technology are the hot spots in cartilage tissue engineering at present.

Ming et al. (2018) prepared PLA/gelatin 3D nanofiber sponge loaded with resveratrol (RES) using the electrostatic spinning technology reported by Chen (Chen et al., 2016c; Chen et al., 2016d). First, $0.1 \mathrm{~g}$ of PLA and $0.75 \mathrm{~g}$ of gelatin were mixed in $9 \mathrm{ml}$ of 1,1,1,3,3,3-hexafluoro-2-propanol with a mass ratio of 1:5 of gelatin to PLA and stirred at room temperature for $5 \mathrm{~h}$ to prepare the PLA/gelatin solution. RES was then added, and the mixture was dissolved in $0.1 \mathrm{ml}$ of ethanol and stirred until uniform. The mixed solution was then loaded into a stainlesssteel needle at a flow rate of $3 \mathrm{ml} / \mathrm{h}$ at an applied voltage of $15 \mathrm{kV}$. The distance between the needle and the collector was $10 \mathrm{~cm}$. All the collected PLA/gelatin nanofiber membranes were placed in a vacuum overnight to remove the residual solvents. The nanofiber membranes prepared as above were cut into small pieces $(0.5 \times$ $0.5 \mathrm{~cm}$ ), then $1 \mathrm{~g}$ of the membranes was weighed and added to $100 \mathrm{ml}$ of tert-Butanol and dispersed by a homogenizer at a speed of $10,000 \mathrm{r} / \mathrm{min}$ for $20 \mathrm{~min}$. The dispersed nanofibers were then poured into a 24-well cell culture plate and freeze-dried for $24 \mathrm{~h}$, and the freeze-dried 3D nanofiber sponge was heated in air at $190^{\circ} \mathrm{C}$ for $2 \mathrm{~h}$ for cross-linking in order to obtain the final scaffold.

Kann et al. (2016) dissolved $2 \mathrm{~g}$ of SA and $6 \mathrm{~g}$ of gelatin (SA/ gel, 1:3 ratio) in $50 \mathrm{ml}$ of $\mathrm{ddH}_{2} \mathrm{O}$ to preprocess the colloid solution. The $3 \mathrm{D}$ printer parameters were set as follows: printing pressure of $0.20-0.40 \mathrm{MPa}$, line spacing of $0.3-1.2 \mathrm{~mm}$, printing diameter of $210-510 \mu \mathrm{m}$, printing speed of $4-16 \mathrm{~mm} / \mathrm{s}$, and printing temperature of $200^{\circ} \mathrm{C}$, kept constant throughout the printing process. The printed SA/gel composite scaffold was promptly soaked in $5 \% \mathrm{CaCl}_{2}$ for $30 \mathrm{~min}$ for rapid solidification, then soaked in $2 \%$ glutaraldehyde for $24 \mathrm{~h}$ for cross-linking. Residual glutaraldehyde was removed via l-glutamate treatment, and the scaffold was freeze-dried. In addition, Zhu et al. (Zhu et al., 2020) first prepared acellular cartilage polyethylene diacrylate (PEGDA)/ECM hydrogel using the optical cross-linking method, then prepared PEGDA/ECM $3 \mathrm{D}$ ink via dynamic projection stereophotography. Moreover, many preparation methods for drug-loading material scaffolds have been widely used in cartilage tissue engineering, such as hydrogel prepared by chemical or photo cross-linking (Goldring and Goldring, 2016) (Rai et al., 2017), aerogel prepared via the sol-gel method (Xia et al., 2014), membrane hydroliposomes (Wang et al., 2013) and NPs prepared by ion cross-linking (Miller et al., 2016).

\subsection{Combination of Botanical Drug Extracts and Carriers}

Through an analysis of the relevant literature, the combination of extracts and carriers is classified into two categories according to the different periods of ingredient addition: reactive combination and cell culture.

I. Reactive combination: This is the method chosen for many studies (Charlier et al., 2019; Jin et al., 2020a; Oliveira Silva et al., 2020). The combination is carried out through a series of chemical reactions between the BDEs and the carrier material preparation. For example, Sheu et al. (Goldring and
Goldring, 2016) dissolved RES and HMDI in a dry tetrahydrofuran solution, slowly heated it to $50^{\circ} \mathrm{C}$ for $50 \mathrm{~h}$, then gradually added $\mathrm{H}_{2} \mathrm{O}$ to the reaction mixture (over $30 \mathrm{~min})$ to generate RES-HMDI- $\mathrm{NH}_{2}$. Oxi-hyaluronan (OXI-HA) solution was then mixed with the RES-HMDI$\mathrm{NH}_{2}$ solution to form an Oxi-HA-RES solution. Finally, the oxidized HA/RES hydrogel was prepared. II. Cell culture: Considering the cytotoxicity of some ingredients, this method is more suitable for confirming safe and nontoxic BDEs, so there are fewer studies. Kann et al. (2016) incubated cells in a normal medium for $24 \mathrm{~h}$. After the cells had adhered normally, they took the medium out and replaced it with a medium containing ICA. After incubation for 1, 3, 5, and 7 days, they observed the cell proliferation. Finally, cells cultured with the extracts were planted on the carrier.

A total of 31 reports were included in this review, among which 12 were not studied in animal models, 17 were tested by IA injection, one was tested by intraperitoneal injection, and the remaining one was a clinical trial. In the selection of carriers, nanoparticles, microspheres, hydrogels, and 3D printed carriers are chosen. It is noteworthy that due to the pathological relationship between low $\mathrm{pH}$ and $\mathrm{OA}$, acid-sensitive hydrogels prepared from mesoporous silica are superior in drug release, anti-inflammatory, and cartilage defect repair properties. The combination of cartilage tissue engineering materials improves the bioavailability of BDEs, prolongs the time of drug action, and alleviates adverse reactions.

We can find that almost all BDEs that can be used to treat OA have anti-inflammatory and antioxidant effects. Among them, CUR, BBR, and HON can not only protect cartilage but also promote the formation of subchondral bone, which is more suitable for the treatment of patients with subchondral bone damage in the advanced stages of OA. In addition, for BRU and CLC, we need to develop more appropriate administration systems to reduce their toxicity. Aside from anti-inflammatory and cartilage protective effects, Hes, SIN, and COR can also induce autophagy in vivo to mitigate the degradation of the cartilage matrix. At present, RES and CUR are the most studied BDEs, but they are still in the animal experiment stage. Further studies are required to confirm our hypotheses on how to further improve efficacy and whether they are clinically feasible (Table 6).

\section{CONCLUSION}

This article reviews the role of BDEs combined with biomaterial carriers in the treatment of $\mathrm{OA}$ and the repair of cartilage degeneration in recent 10 years. Many studies have shown that BDEs play an anti-inflammatory, anti-oxidation, and cartilage protection role by inhibiting the expression of pro-inflammatory factors (IL-1 $\beta$, IL-6, and TNF- $\alpha$ ) and matrix degrading enzymes (MMP1, MMP3, MMP13, and COX-2), and removing oxidative stress substances such as $\mathrm{NO}$, ROS, and $\mathrm{H}_{2} \mathrm{O}_{2}$. They can also promote the repair of cartilage degeneration and delay the progress of OA by regulating chondrocyte autophagy. Some BDEs (e.g. RES, CUR, ICA, and Hes) can also promote the 
TABLE 5 | The effect of other effective components of traditional Chinese medicine combined with carriers on OA cartilage repair.

\begin{tabular}{|c|c|c|c|c|c|c|c|}
\hline \multirow{2}{*}{$\begin{array}{l}\text { Research } \\
\text { (author \& } \\
\text { year) }\end{array}$} & \multirow[t]{2}{*}{ BDEs } & \multirow[t]{2}{*}{ Carrier } & \multicolumn{2}{|c|}{ Gene expression } & \multicolumn{2}{|c|}{ Cartilage repair effects } & \multirow[t]{2}{*}{ Research conclusion } \\
\hline & & & Inhibition & Promote & Imaging evaluations & Tissue sections & \\
\hline $\begin{array}{l}\text { Amorndoljai } \\
\text { et al. (2015) }\end{array}$ & GINE & NLC & & & No mention & No mention & $\begin{array}{l}\text { GINE nanoparticles } \\
\text { alleviated joint pain, } \\
\text { improved symptoms } \\
\text { of KOA }\end{array}$ \\
\hline He et al. (2021) & $A G$ & $\begin{array}{l}\text { MSNs- } \\
\text { PAA }\end{array}$ & $\mathrm{IL}-1 \beta, \mathrm{MMPs}$ & $\begin{array}{l}\text { Col.Il, } \\
\text { GAG, } \\
\text { ACAN }\end{array}$ & $\begin{array}{l}\text { AG@MSNs-PAA displayed } \\
\text { minimal changes in cartilage } \\
\text { compared to the other three } \\
\text { ACLT groups by general } \\
\text { observation }\end{array}$ & $\begin{array}{l}\text { Matrix vertical fissures, thinner } \\
\text { cartilage as well as minor surface } \\
\text { destabilization were observed }\end{array}$ & $\begin{array}{l}\text { AG@MSNs-PAA can } \\
\text { effectively inhibit the } \\
\text { development of OA }\end{array}$ \\
\hline $\begin{array}{l}\text { Kulsirirat et al. } \\
\text { (2021a) }\end{array}$ & AG & $\begin{array}{l}\text { PLGA- } \\
\text { NPs }\end{array}$ & & & No mention & No mention & $\begin{array}{l}\text { AG-NPs-PLGA can } \\
\text { prolong the duration to } \\
\text { improve the therapeutic } \\
\text { efficacy }\end{array}$ \\
\hline Xia et al. (2017) & COR & $\begin{array}{l}\text { CM- } \\
\text { HAMA }\end{array}$ & $\begin{array}{l}\text { IL-1 } 1 \beta, \text { MMPs, } \\
\text { ADAMTS5 }\end{array}$ & $\begin{array}{l}\text { Col.II, LC3, } \\
\text { ACAN }\end{array}$ & No mention & $\begin{array}{l}\text { In comparison with IL } 1 \text { - } \beta \text {-treated } \\
\text { cartilage, cartilage that was } \\
\text { simultaneously treated with IL1- } \beta \\
\text { and COR exhibited more Safranin- } \\
\text { O-positive proteoglycan }\end{array}$ & $\begin{array}{l}\text { COR improves cartilage } \\
\text { matrix degradation by } \\
\text { inducing autophagy }\end{array}$ \\
\hline Zhang (2017) & TMP & $\begin{array}{l}\text { PLGA- } \\
\text { Ms }\end{array}$ & & & No mention & $\begin{array}{l}\text { The cartilage damage was } \\
\text { improved in the treatment group } \\
\text { compared to the untreated OA } \\
\text { model; the cartilage layer } \\
\text { recovered integrity and } \\
\text { chondrocytes arranged in normal }\end{array}$ & $\begin{array}{l}\text { IA injection of TMP } \\
\text { microspheres can } \\
\text { effectively relieve } \\
\text { inflammatory symptoms }\end{array}$ \\
\hline $\begin{array}{l}\text { Jin et al. } \\
\text { (2020a) }\end{array}$ & CSL & $\begin{array}{l}\text { MSNs- } \\
\text { Cs }\end{array}$ & 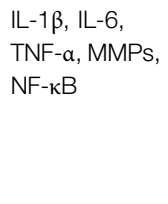 & & $\begin{array}{l}\text { A profoundly reduced knee } \\
\text { swelling and improvement in } \\
\text { synovial inflammation and } \\
\text { cartilage integrity were } \\
\text { demonstrated in the CSL@ } \\
\text { HMSNs-CS group by MRI }\end{array}$ & $\begin{array}{l}\text { A dramatic improvement in } \\
\text { pathological changes, such as } \\
\text { smooth cartilage surface, } \\
\text { undulating tide line, and cartilage } \\
\text { thickness was observed in the } \\
\text { CSL@HMSNs-CS group }\end{array}$ & $\begin{array}{l}\text { HMSNs-Cs can improve } \\
\text { the solubility and } \\
\text { bioavailability of CSL }\end{array}$ \\
\hline $\begin{array}{l}\text { Bairwa and } \\
\text { Jachak, } 2016\end{array}$ & KBA & $\begin{array}{l}\text { PLAG- } \\
\text { NPs }\end{array}$ & & & No mention & No mention & $\begin{array}{l}\text { The bioavailability and anti- } \\
\text { inflammatory activity of } \\
\text { KBA in KBA-NPs were } \\
\text { increased }\end{array}$ \\
\hline
\end{tabular}

AG@MSNs-PAA, andrographolide-loaded mesoporous silica nanoparticles with pH-responsive PAA; PLGA, poly(lactic-co-glycolic acid); PLGA-NPs, PLGA nanoparticle-gelatin hydrogel; CM, chitosan microspheres; HAMA, HA methacrylate; PLGA-Ms, PLGA microspheres; MSNs-Cs, mesoporous silica nanoparticles-chitosan; PLAG-NPs, PLAG-polyvinyl alcohol nanoparticles; HMSNS-Cs, Hollow mesoporous silica nanoparticles capped with chitosan; CSL@HMSNs-CS, celastrol loaded HMSNS-Cs.

production of COL2 in the cartilage ECM, thus promoting the production of hyaline cartilage (instead of fibrocartilage) at the defect site, which is very beneficial to the recovery of normal joint function. In addition, a few BDEs, such as CUR, HON, and BBR, play an osteogenic role through OPG/RANKL and $\mathrm{Wnt} / \beta$ catenin signaling pathways and promote the repair of subchondral bone defects, so they are more suitable for the injury of subchondral bone involved in late OA. At present, the clinical drugs used for OA treatment are mostly limited to symptomatic treatment to relieve joint pain and improve joint function. Comparatively, BDEs can not only improve the joint function and eliminate clinical symptoms but also promote the repair of damaged cartilage in multiple ways and targets, and delay the progress of OA.

Since the progression of OA is a long-term, chronic process, the patients need long-term administration. However, oral administration has poor bioavailability and long-term oral administration can cause some serious adverse reactions. On the contrary, local IA injection or drug carrier implantation greatly improves drug utilization and reduces systemic response. Compared with local injection of pure BDEs, the sustained-release effect of the biomaterial carrier can enhance the retention time of the drug in the joints and enable the drug to function stably for a long time. So how to choose IA injection or drug carrier implantation? The attributes of OA determine a long-term treatment and delaying the progress of $\mathrm{OA}$ is the focus of the current clinical treatment. In combination with the included studies, it is more appropriate to select IA injection of drug-carrying biomaterial carriers (hydrogels, nanoparticles, microspheres, etc.) when cartilage damage is not serious in the early and middle stages of OA. Because it is easier to perform than surgical treatment, long-term and repeated injection therapy is possible. For the damage involving subchondral bone in the late stage of $\mathrm{OA}$, the drug carrier implantation is recommended. Compared with the current clinical knee replacement for patients with late OA, drug carrier implantation is theoretically more conducive to the recovery of joint function in patients without worrying about prosthetic wear. 
TABLE 6 | A summary of key advancements in the field.

\begin{tabular}{|c|c|c|}
\hline Category & Key advancements & References \\
\hline \multirow[t]{5}{*}{$\begin{array}{l}\text { Herbal } \\
\text { monomer }\end{array}$} & $\begin{array}{l}\text { CUR and RES are the most used herbal monomers in cartilage repair, and the optimal concentration of } \\
\text { RES is } 114.281 \mathrm{~mol} / \mathrm{L}\end{array}$ & Ming et al. (2018) \\
\hline & $\begin{array}{l}\text { Coencapsulated RES and CUR in lipomolecular nanocapsules, improved the photostability of RES and } \\
\text { the in vitro antioxidant activity of both polyphenols }\end{array}$ & Coradini et al. (2015), Kann et al. (2016) \\
\hline & CUR, BBR, and HON can not only protect cartilage but also promote the formation of subchondral bone & $\begin{array}{l}\text { Chen et al. (2012), Yeh et al. (2015), Zhu et al. } \\
\text { (2020) }\end{array}$ \\
\hline & Both BRU and CLC have severe biotoxicity, pay attention to test its safety & Chen et al. (2012), Mohamed et al. (2020) \\
\hline & Hes, SIN, and COR can induce autophagy in vivo to improve the degradation of the cartilage matrix & $\begin{array}{l}\text { Chen (2015), Xia et al. (2017), Ouyang et al. } \\
\text { (2019) }\end{array}$ \\
\hline \multirow[t]{7}{*}{ Carriers } & $\begin{array}{l}\text { GD2(CO3)3@PDA-a gadolinium (III) (Gd3+) containing MRI contrast agent coated with PDA, a good } \\
\text { drug carrier for the targeted delivery of OA drugs to lesion sites }\end{array}$ & Ouyang et al. (2019) \\
\hline & $\begin{array}{l}\text { Prepared a high porosity 3D scaffold based on cellular responsive polymer ink SA and gelatin (SA-gel, } \\
1: 3)\end{array}$ & Kankala et al. (2018) \\
\hline & The use of PLA can enhance the bioabsorbability and drug carrying capacity of nanoparticles & Kamel et al. (2019) \\
\hline & Microfluidic drug screening device can effectively screen the drug concentration required for cell culture & Ming et al. (2018) \\
\hline & $\begin{array}{l}\text { The thermosensitive composite hydrogel prepared with chitosan as temperature-sensitive material can } \\
\text { change the distribution of drugs in the joint cavity, increase the concentration of drugs in the joint cavity, } \\
\text { and delay the retention of drugs in the target region }\end{array}$ & Chen et al. (2012) \\
\hline & $\begin{array}{l}\text { PAE can be used to achieve controlled drug release at low } \mathrm{PH} \text {, and the positively charged PAE can } \\
\text { interact with the GAG in the cartilage by electrostatic interaction to achieve targeted drug delivery }\end{array}$ & Kang (2019) \\
\hline & $\begin{array}{l}\text { AG@MSNs-PAA nanoplatform formed by modified MSNs and pH-responsive PAA is favorable for } \\
\text { sustained release in the OA environment }\end{array}$ & Jin (2020), He et al. (2021) \\
\hline
\end{tabular}

PDA, polydopamine; AG@MSNs-PAA, andrographolide-loaded mesoporous silica nanoparticles with pH-responsive PAA.

However, long-term repeated injections tend to cause local infection and reduce patient compliance. Therefore, the optimal injection cycle, dose, and times of IA injection need further study and confirmation. It is worth noting that IA injection means that the injection has certain fluidity, so how to improve its biological response, targeting, and mechanical properties is a problem that researchers need to further explore. In addition, because of the irregularity of cartilage damage, the degradability of drug carrier, the biomechanical characteristics of local knee joints, and the different structures of cartilage layers in OA patients, the structural distribution of each layer, the optimal degradation rate, the compatibility and adhesion between the carriers and surrounding tissues need further research during stent fabrication.

It is found in the included studies that almost all researchers chose chondrocytes rather than MSCs in the selection of seed cells. However, many studies have confirmed that MSCs as seed cells are more suitable for cartilage repair. Then, whether BDEs can promote or induce the differentiation of MSCs into chondrocytes and the related mechanism of action are also questions worthy of consideration. In addition, because the mechanism of action of most BDEs (some having certain toxicity) has not been fully understood yet, the rejection reaction of the body, as well as the changes in the biological environment, chemical stimulation, and microenvironment in the damaged area, researchers need to further study and confirm the selection and manufacture of materials; the selection, dose, concentration, etc. of BDEs. At present, all in vivo animal studies have confirmed the effectiveness and safety of BDEs combined with biomaterial carriers, but there is no related clinical experiment to further verify their effectiveness and safety. Therefore, more relevant studies are needed to address the current problems.

\section{AUTHOR CONTRIBUTIONS}

$\mathrm{PM}$ and YH confirmed the review direction; PM and JF consulted and screened relevant literature, and XM, FX, and LT assisted in data extraction; PM completed the design of manuscript writing, pictures, tables, etc.; YH put forward suggestions on the revision of the manuscript and confirmed the final draft.

\section{FUNDING}

The research is funded by Sichuan Provincial Administration of Traditional Chinese Medicine, with the project number 2021MS454, and the special fund for 100 Talents Program of the First Affiliated Hospital of Chengdu University of TCM, with the project number $20-Y 14$.

\section{ACKNOWLEDGMENTS}

The authors thank all participants for their help during the writing of the article and thank the central administration of Sichuan Province and the Affiliated Hospital of Chengdu University of Traditional Chinese Medicine for their financial support.

\section{SUPPLEMENTARY MATERIAL}

The Supplementary Material for this article can be found online at: https://www.frontiersin.org/articles/10.3389/fphar.2021.789311/ full\#supplementary-material 


\section{REFERENCES}

Abdulbaqi, I. M., Darwis, Y., Assi, R. A., and Khan, N. A. K. (2018). Transethosomal Gels as Carriers for the Transdermal Delivery of Colchicine: Statistical Optimization, Characterization, and Ex Vivo Evaluation. Drug Des. Devel Ther. 12, 795-813. doi:10.2147/DDDT.S158018

Abed, É., Delalandre, A., and Lajeunesse, D. (2017). Beneficial Effect of Resveratrol on Phenotypic Features and Activity of Osteoarthritic Osteoblasts. Arthritis Res. Ther. 19 (1), 151. doi:10.1186/s13075-017-1365-2

Abramson, S. B. (2008). Osteoarthritis and Nitric Oxide. Osteoarthritis Cartilage 16 Suppl 2, S15-S20. doi:10.1016/S1063-4584(08)60008-4

Aggarwal, B. B., Gupta, S. C., and Sung, B. (2013). Curcumin: an Orally Bioavailable Blocker of TNF and Other Pro-inflammatory Biomarkers. $\mathrm{Br}$. J. Pharmacol. 169 (8), 1672-1692. doi:10.1111/bph.12131

Ahmed, S., Rahman, A., Hasnain, A., Lalonde, M., Goldberg, V. M., and Haqqi, T. M. (2002). Green tea Polyphenol Epigallocatechin-3-Gallate Inhibits the IL-1 Beta-Induced Activity and Expression of Cyclooxygenase-2 and Nitric Oxide Synthase-2 in Human Chondrocytes. Free Radic. Biol. Med. 33 (8), 1097-1105. doi:10.1016/s0891-5849(02)01004-3

Akhtar, N., and Haqqi, T. M. (2011). Epigallocatechin-3-gallate Suppresses the Global Interleukin-1beta-Induced Inflammatory Response in Human Chondrocytes. Arthritis Res. Ther. 13 (3), R93. doi:10.1186/ar3368

Ammon, H. P. (2010). Modulation of the Immune System by Boswellia Serrata Extracts and Boswellic Acids. Phytomedicine 17 (11), 862-867. doi:10.1016/ j.phymed.2010.03.003

Amorndoljai, P., Taneepanichskul, S., Niempoog, S., and Nimmannit, U. (2015). Improving of Knee Osteoarthritic Symptom by the Local Application of Ginger Extract Nanoparticles: A Preliminary Report with Short Term Follow-Up. J. Med. Assoc. Thai 98 (9), 871-877.

Anand, P., Kunnumakkara, A. B., Newman, R. A., and Aggarwal, B. B. (2007). Bioavailability of Curcumin: Problems and Promises. Mol. Pharm. 4 (6), 807-818. doi:10.1021/mp700113r

Andres, S., Pevny, S., Ziegenhagen, R., Bakhiya, N., Schäfer, B., Hirsch-Ernst, K. I., et al. (2018). Safety Aspects of the Use of Quercetin as a Dietary Supplement. Mol. Nutr. Food Res. 62 (1). doi:10.1002/mnfr.201700447

Ashraf, S., Radhi, M., Gowler, P., Burston, J. J., Gandhi, R. D., Thorn, G. J., et al. (2019). The Polyadenylation Inhibitor Cordycepin Reduces Pain, Inflammation and Joint Pathology in Rodent Models of Osteoarthritis. Sci. Rep. 9 (1), 4696. doi:10.1038/s41598-019-41140-1

Bae, S. C., Jung, W. J., Lee, E. J., Yu, R., and Sung, M. K. (2009). Effects of Antioxidant Supplements Intervention on the Level of Plasma Inflammatory Molecules and Disease Severity of Rheumatoid Arthritis Patients. J. Am. Coll. Nutr. 28 (1), 56-62. doi:10.1080/07315724.2009.10719762

Bairwa, K., and Jachak, S. M. (2016). Nanoparticle Formulation of 11-Keto- $\beta$ Boswellic Acid (KBA): Anti-inflammatory Activity and In Vivo Pharmacokinetics. Pharm. Biol. 54 (12), 2909-2916. doi:10.1080/ 13880209.2016.1194437

Bannuru, R. R., Osani, M. C., Al-Eid, F., and Wang, C. (2018). Efficacy of Curcumin and Boswellia for Knee Osteoarthritis: Systematic Review and Meta-Analysis. Semin. Arthritis Rheum. 48 (3), 416-429. doi:10.1016/j.semarthrit.2018.03.001

Bannuru, R. R., Osani, M. C., Vaysbrot, E. E., Arden, N. K., Bennell, K., BiermaZeinstra, S. M. A., et al. (2019). OARSI Guidelines for the Non-surgical Management of Knee, Hip, and Polyarticular Osteoarthritis. Osteoarthritis Cartilage 27 (11), 1578-1589. doi:10.1016/j.joca.2019.06.011

Bartels, E. M., Folmer, V. N., Bliddal, H., Altman, R. D., Juhl, C., Tarp, S., et al. (2015). Efficacy and Safety of Ginger in Osteoarthritis Patients: a Meta-Analysis of Randomized Placebo-Controlled Trials. Osteoarthritis Cartilage 23 (1), 13-21. doi:10.1016/j.joca.2014.09.024

Belcaro, G., Cesarone, M. R., Dugall, M., Pellegrini, L., Ledda, A., Grossi, M. G., et al. (2010). Efficacy and Safety of Meriva ${ }^{\circledR}$, a Curcumin-Phosphatidylcholine Complex, during Extended Administration in Osteoarthritis Patients. Altern. Med. Rev. 15 (4), 337-344.

Belwal, T., Bisht, A., Devkota, H. P., Ullah, H., Khan, H., Pandey, A., et al. (2020). Phytopharmacology and Clinical Updates of Berberis Species against Diabetes and Other Metabolic Diseases. Front. Pharmacol. 11, 41. doi:10.3389/ fphar.2020.00041
Berenbaum, F., Grifka, J., Cazzaniga, S., D’Amato, M., Giacovelli, G., Chevalier, X., et al. (2012). A Randomised, Double-Blind, Controlled Trial Comparing Two Intra-articular Hyaluronic Acid Preparations Differing by Their Molecular Weight in Symptomatic Knee Osteoarthritis. Ann. Rheum. Dis. 71 (9), 1454-1460. doi:10.1136/annrheumdis-2011-200972

Blanco, F. J., Rego, I., and Ruiz-Romero, C. (2011). The Role of Mitochondria in Osteoarthritis. Nat. Rev. Rheumatol. 7 (3), 161-169. doi:10.1038/ nrrheum.2010.213

Bliddal, H., Rosetzsky, A., Schlichting, P., Weidner, M. S., Andersen, L. A., Ibfelt, H. H., et al. (2000). A Randomized, Placebo-Controlled, Cross-Over Study of Ginger Extracts and Ibuprofen in Osteoarthritis. Osteoarthritis Cartilage 8 (1), 9-12. doi:10.1053/joca.1999.0264

Britti, D., Crupi, R., Impellizzeri, D., Gugliandolo, E., Fusco, R., Schievano, C., et al. (2017). A Novel Composite Formulation of Palmitoylethanolamide and Quercetin Decreases Inflammation and Relieves Pain in Inflammatory and Osteoarthritic Pain Models. BMC Vet. Res. 13 (1), 229. doi:10.1186/s12917-0171151-z

Bugbee, W. D., Pallante-Kichura, A. L., Görtz, S., Amiel, D., and Sah, R. (2016). Osteochondral Allograft Transplantation in Cartilage Repair: Graft Storage Paradigm, Translational Models, and Clinical Applications. J. Orthop. Res. 34 (1), 31-38. doi:10.1002/jor.22998

Buhrmann, C., Honarvar, A., Setayeshmehr, M., Karbasi, S., Shakibaei, M., and Valiani, A. (2020). Herbal Remedies as Potential in Cartilage Tissue Engineering: An Overview of New Therapeutic Approaches and Strategies. Molecules 25 (13). doi:10.3390/molecules25133075

Burgos, R. A., Alarcón, P., Quiroga, J., Manosalva, C., and Hancke, J. (2020). Andrographolide, an Anti-inflammatory Multitarget Drug: All Roads Lead to Cellular Metabolism. Molecules 26 (1). doi:10.3390/molecules26010005

Burt, H. M., Tsallas, A., Gilchrist, S., and Liang, L. S. (2009). Intra-articular Drug Delivery Systems: Overcoming the Shortcomings of Joint Disease Therapy. Expert Opin. Drug Deliv. 6 (1), 17-26. doi:10.1517/17425240802647259

Cameron, M., and Chrubasik, S. (2014). Oral Herbal Therapies for Treating Osteoarthritis. Cochrane Database Syst. Rev. 5 (5), Cd002947. doi:10.1002/ 14651858.CD002947.pub2

Charlier, E., Deroyer, C., Ciregia, F., Malaise, O., Neuville, S., Plener, Z., et al. (2019). Chondrocyte Dedifferentiation and Osteoarthritis (OA). Biochem. Pharmacol. 165, 49-65. doi:10.1016/j.bcp.2019.02.036

Chen, B., Zhan, H., Marszalek, J., Chung, M., Lin, X., Zhang, M., et al. (2016a). Traditional Chinese Medications for Knee Osteoarthritis Pain: A Meta-Analysis of Randomized Controlled Trials. Am. J. Chin. Med. 44 (4), 677-703. doi:10.1142/S0192415X16500373

Chen, P., Xia, C., Mei, S., Wang, J., Shan, Z., Lin, X., et al. (2016b). Intra-articular Delivery of Sinomenium Encapsulated by Chitosan Microspheres and PhotoCrosslinked GelMA Hydrogel Ameliorates Osteoarthritis by Effectively Regulating Autophagy. Biomaterials 81, 1-13. doi:10.1016/ j.biomaterials.2015.12.006

Chen, W., Chen, S., Morsi, Y., El-Hamshary, H., El-Newhy, M., Fan, C., et al. (2016c). Superabsorbent 3D Scaffold Based on Electrospun Nanofibers for Cartilage Tissue Engineering. ACS Appl. Mater. Interfaces 8 (37), 24415-25415.

Chen, W., Ma, J., Zhu, L., Morsi, Y., Ei-Hamshary, H., Al-Deyab, S. S., et al. (2016d). Superelastic, Superabsorbent and 3D Nanofiber-Assembled Scaffold for Tissue Engineering. Colloids Surf B Biointerfaces 142, 165-172.

Chen, L., Liu, J., Guan, M., Zhou, T., Duan, X., and Xiang, Z. (2020). Growth Factor and its Polymer Scaffold-Based Delivery System for Cartilage Tissue Engineering. Int. J. Nanomedicine 15, 6097-6111. doi:10.2147/IJN.S249829

Chen, L., Liu, T., Wang, Q., and Liu, J. (2017). Anti-inflammatory Effect of Combined Tetramethylpyrazine, Resveratrol and Curcumin In Vivo. BMC Complement. Altern. Med. 17 (1), 233. doi:10.1186/s12906-017-1739-7

Chen, P., Xia, C., Mo, J., Mei, S., Lin, X., and Fan, S. (2018). Interpenetrating Polymer Network Scaffold of Sodium Hyaluronate and Sodium Alginate Combined with Berberine for Osteochondral Defect Regeneration. Mater. Sci. Eng. C Mater. Biol. Appl. 91, 190-200. doi:10.1016/j.msec.2018.05.034

Chen, S., Luo, Z., and Chen, X. (2020). Andrographolide Mitigates Cartilage Damage via miR-27-3p-Modulated Matrix Metalloproteinase13 Repression. J. Gene Med. 22 (8), e3187. doi:10.1002/jgm.3187

Chen, Y. J., Tsai, K. S., Chan, D. C., Lan, K. C., Chen, C. F., Yang, R. S., et al. (2014). Honokiol, a Low Molecular Weight Natural Product, Prevents Inflammatory 
Response and Cartilage Matrix Degradation in Human Osteoarthritis Chondrocytes. J. Orthop. Res. 32 (4), 573-580. doi:10.1002/jor.22577

Chen, Z. P., Liu, W., Liu, D., Xiao, Y. Y., Chen, H. X., Chen, J., et al. (2012). Development of Brucine-Loaded Microsphere/thermally Responsive Hydrogel Combination System for Intra-articular Administration. J. Control. Release 162 (3), 628-635. doi:10.1016/j.jconrel.2012.07.037

Chin, K. Y. (2016). The Spice for Joint Inflammation: Anti-inflammatory Role of Curcumin in Treating Osteoarthritis. Drug Des. Devel Ther. 10, 3029-3042. doi:10.2147/DDDT.S117432

Coradini, K., Friedrich, R. B., Fonseca, F. N., Vencato, M. S., Andrade, D. F., Oliveira, C. M., et al. (2015). A Novel Approach to Arthritis Treatment Based on Resveratrol and Curcumin Co-encapsulated in Lipid-Core Nanocapsules: In Vivo Studies. Eur. J. Pharm. Sci. 78, 163-170. doi:10.1016/j.ejps.2015.07.012

Crivelli, B., Bari, E., Perteghella, S., Catenacci, L., Sorrenti, M., Mocchi, M., et al. (2019). Silk Fibroin Nanoparticles for Celecoxib and Curcumin Delivery: ROSScavenging and Anti-inflammatory Activities in an In Vitro Model of Osteoarthritis. Eur. J. Pharm. Biopharm. 137, 37-45. doi:10.1016/ j.ejpb.2019.02.008

Das, S. K., Mishra, K., Ramakrishnan, S., Srivastava, R., Agarwal, G. G., Singh, R., et al. (2002). A Randomized Controlled Trial to Evaluate the Slow-Acting Symptom Modifying Effects of a Regimen Containing Colchicine in a Subset of Patients with Osteoarthritis of the Knee. Osteoarthritis Cartilage 10 (4), 247-252. doi:10.1053/joca.2002.0516

Di Martino, A., Silva, S., Andriolo, L., Merli, G., Reale, D., Zaffagnini, S., et al. (2021). Osteochondral Autograft Transplantation versus Autologous BoneCartilage Paste Grafting for the Treatment of Knee Osteochondritis Dissecans. Int. Orthop. 45 (2), 453-461. doi:10.1007/s00264-020-04804-6

Ding, Q. H., Ji, X. W., Cheng, Y., Yu, Y. Q., Qi, Y. Y., and Wang, X. H. (2013). Inhibition of Matrix Metalloproteinases and Inducible Nitric Oxide Synthase by Andrographolide in Human Osteoarthritic Chondrocytes. Mod. Rheumatol. 23 (6), 1124-1132. doi:10.1007/s10165-012-0807-6

Efferth, T., and Oesch, F. (2020). Anti-inflammatory and Anti-cancer Activities of Frankincense: Targets, Treatments and Toxicities. Semin. Cancer Biol. doi:10.1016/j.semcancer.2020.01.015

Elmali, N., Baysal, O., Harma, A., Esenkaya, I., and Mizrak, B. (2007). Effects of Resveratrol in Inflammatory Arthritis. Inflammation 30 (1-2), 1-6. doi:10.1007/ s10753-006-9012-0

Evans, T. I., Wheeler, M. T., Small, R. E., Breitbach, S. A., Sanders, K. M., and Roberts, W. N. (1996). A Comprehensive Investigation of Inpatient Intravenous Colchicine Use Shows More Education Is Needed. J. Rheumatol. 23 (1), 143-148.

Feng, K., Chen, H., and Xu, C. (2020). Chondro-protective Effects of Celastrol on Osteoarthritis through Autophagy Activation and NF-Kb Signaling Pathway Inhibition. Inflamm. Res. 69 (4), 385-400. doi:10.1007/s00011-020-01327-z

Feng, K., Chen, Z., Pengcheng, L., Zhang, S., and Wang, X. (2019). Quercetin Attenuates Oxidative Stress-Induced Apoptosis via SIRT1/AMPK-Mediated Inhibition of ER Stress in Rat Chondrocytes and Prevents the Progression of Osteoarthritis in a Rat Model. J. Cel Physiol 234 (10), 18192-18205. doi:10.1002/jcp. 28452

Feng, K., Ge, Y., Chen, Z., Li, X., Liu, Z., Li, X., et al. (2019). Curcumin Inhibits the PERK-eIF2 $\alpha$-CHOP Pathway through Promoting SIRT1 Expression in Oxidative Stress-Induced Rat Chondrocytes and Ameliorates Osteoarthritis Progression in a Rat Model. Oxid Med. Cel Longev 2019, 8574386. doi:10.1155/ 2019/8574386

Frehner, F., and Benthien, J. P. (2018). Microfracture: State of the Art in Cartilage Surgery? Cartilage 9 (4), 339-345. doi:10.1177/1947603517700956

Gao, L., Lin, Y., Wang, S., Lin, L., Lu, D., Zhao, Y., et al. (2021). Chronotoxicity of Semen Strychni Is Associated with Circadian Metabolism and Transport in Mice. J. Pharm. Pharmacol. 73 (3), 398-409. doi:10.1093/jpp/rgaa007

Goldring, S. R., and Goldring, M. B. (2016). Changes in the Osteochondral Unit during Osteoarthritis: Structure, Function and Cartilage-Bone Crosstalk. Nat. Rev. Rheumatol. 12 (11), 632-644. doi:10.1038/nrrheum.2016.148

Gong, Y., and Gluud, C. (2004). Colchicine for Primary Biliary Cirrhosis. Cochrane Database Syst. Rev. (2), Cd004481. doi:10.1002/14651858.CD004481.pub2

Grover, A. K., and Samson, S. E. (2016). Benefits of Antioxidant Supplements for Knee Osteoarthritis: Rationale and Reality. Nutr. J. 15, 1. doi:10.1186/s12937015-0115-z
Gu, H., Jiao, Y., Yu, X., Li, X., Wang, W., Ding, L., et al. (2017). Resveratrol Inhibits the IL-1 $\beta$-induced Expression of MMP-13 and IL- 6 in Human Articular Chondrocytes via TLR4/MyD88-dependent and -independent Signaling Cascades. Int. J. Mol. Med. 39 (3), 734-740. doi:10.3892/ijmm.2017.2885

Gupte, P. A., Giramkar, S. A., Harke, S. M., Kulkarni, S. K., Deshmukh, A. P., Hingorani, L. L., et al. (2019). Evaluation of the Efficacy and Safety of Capsule Longvida ${ }^{\circledR}$ Optimized Curcumin (Solid Lipid Curcumin Particles) in Knee Osteoarthritis: a Pilot Clinical Study. J. Inflamm. Res. 12, 145-152. doi:10.2147/ JIR.S205390

Hancke, J. L., Srivastav, S., Cáceres, D. D., and Burgos, R. A. (2019). A DoubleBlind, Randomized, Placebo-Controlled Study to Assess the Efficacy of Andrographis Paniculata Standardized Extract $\left(\right.$ ParActin $\left.^{\circledR}\right)$ on Pain Reduction in Subjects with Knee Osteoarthritis. Phytother Res. 33 (5), 1469-1479. doi:10.1002/ptr.6339

Hasanzadeh, S., Read, M. I., Bland, A. R., Majeed, M., Jamialahmadi, T., and Sahebkar, A. (2020). Curcumin: an Inflammasome Silencer. Pharmacol. Res. 159, 104921. doi:10.1016/j.phrs.2020.104921

He, M., Qin, Z., Liang, X., He, X., Zhu, B., Lu, Z., et al. (2021). A pH-Responsive Mesoporous Silica Nanoparticles-Based Drug Delivery System with Controlled Release of Andrographolide for OA Treatment. Regen. Biomater. 8 (4), rbab020. doi:10.1093/rb/rbab020

Heinecke, L. F., Grzanna, M. W., Au, A. Y., Mochal, C. A., Rashmir-Raven, A., and Frondoza, C. G. (2010). Inhibition of Cyclooxygenase-2 Expression and Prostaglandin E2 Production in Chondrocytes by Avocado Soybean Unsaponifiables and Epigallocatechin Gallate. Osteoarthritis Cartilage 18 (2), 220-227. doi:10.1016/j.joca.2009.08.015

Henrotin, Y., Malaise, M., Wittoek, R., de Vlam, K., Brasseur, J. P., Luyten, F. P., et al. (2019). Bio-optimized Curcuma Longa Extract Is Efficient on Knee Osteoarthritis Pain: a Double-Blind Multicenter Randomized Placebo Controlled Three-Arm Study. Arthritis Res. Ther. 21 (1), 179. doi:10.1186/ s13075-019-1960-5

Hosseinzadeh, A., Bahrampour Juybari, K., Fatemi, M. J., Kamarul, T., Bagheri, A., Tekiyehmaroof, N., et al. (2017). Protective Effect of Ginger (Zingiber Officinale Roscoe) Extract against Oxidative Stress and Mitochondrial Apoptosis Induced by Interleukin-1 $\beta$ in Cultured Chondrocytes. Cells Tissues Organs 204 (5-6), 241-250. doi:10.1159/000479789

Hu, P., Chen, W., Bao, J., Jiang, L., and Wu, L. (2014). Cordycepin Modulates Inflammatory and Catabolic Gene Expression in Interleukin-1beta-Induced Human Chondrocytes from Advanced-Stage Osteoarthritis: an In Vitro Study. Int. J. Clin. Exp. Pathol. 7 (10), 6575-6584.

Hu, P. F., Chen, W. P., Tang, J. L., Bao, J. P., and Wu, L. D. (2011). Protective Effects of Berberine in an Experimental Rat Osteoarthritis Model. Phytother Res. 25 (6), 878-885. doi:10.1002/ptr.3359

Hu, Y., Gui, Z., Zhou, Y., Xia, L., Lin, K., and Xu, Y. (2019). Quercetin Alleviates Rat Osteoarthritis by Inhibiting Inflammation and Apoptosis of Chondrocytes, Modulating Synovial Macrophages Polarization to M2 Macrophages. Free Radic. Biol. Med. 145, 146-160. doi:10.1016/j.freeradbiomed.2019.09.024

Hussain, S. A., Marouf, B. H., Ali, Z. S., and Ahmmad, R. S. (2018). Efficacy and Safety of Co-administration of Resveratrol with Meloxicam in Patients with Knee Osteoarthritis: a Pilot Interventional Study. Clin. Interv. Aging 13, 1621-1630. doi:10.2147/CIA.S172758

Javadi, F., Eghtesadi, S., Ahmadzadeh, A., Aryaeian, N., Zabihiyeganeh, M., Foroushani, A. R., et al. (2014). The Effect of Quercetin on Plasma Oxidative Status, C-Reactive Protein and Blood Pressure in Women with Rheumatoid Arthritis. Int. J. Prev. Med. 5 (3), 293-301.

Jhang, J. J., Lu, C. C., and Yen, G. C. (2016). Epigallocatechin Gallate Inhibits Urate Crystals-Induced Peritoneal Inflammation in C57BL/6 Mice. Mol. Nutr. Food Res. 60 (10), 2297-2303. doi:10.1002/mnfr.201600106

Ji, L., Li, W., Qian, W., Feng, S., Shi, H., Wang, Y., et al. (2021). The Role of NanoparticlesMediated Ligustrazine in the Treatment of Knee Osteoarthritis and its Effect on Matrix Metalloproteinases and Upstream NF-Kb Signaling Pathway in Knee Osteoarthritis. J. Nanosci Nanotechnol 21 (2), 1372-1377. doi:10.1166/jnn.2021.18647

Jiang, W., Fan, W., Gao, T., Li, T., Yin, Z., Guo, H., et al. (2020). Analgesic Mechanism of Sinomenine against Chronic Pain. Pain Res. Manag. 2020 1876862. doi:10.1155/2020/1876862

Jin, G. Z. (2020). Current Nanoparticle-Based Technologies for Osteoarthritis Therapy. Nanomaterials (Basel) 10 (12). doi:10.3390/nano10122368 
Jin, T., Wu, D., Liu, X. M., Xu, J. T., Ma, B. J., Ji, Y., et al. (2020). Intra-articular Delivery of Celastrol by Hollow Mesoporous Silica Nanoparticles for $\mathrm{pH}$ Sensitive Anti-inflammatory Therapy against Knee Osteoarthritis. J. Nanobiotechnology 18 (1), 94. doi:10.1186/s12951-020-00651-0

Jin, Y., Koh, R. H., Kim, S. H., Kim, K. M., Park, G. K., and Hwang, N. S. (2020). Injectable Anti-inflammatory Hyaluronic Acid Hydrogel for Osteoarthritic Cartilage Repair. Mater. Sci. Eng. C Mater. Biol. Appl. 115, 111096. doi:10.1016/j.msec.2020.111096

Jones, I. A., Togashi, R., Wilson, M. L., Heckmann, N., and Vangsness, C. T., Jr (2019). Intra-articular Treatment Options for Knee Osteoarthritis. Nat. Rev. Rheumatol. 15 (2), 77-90. doi:10.1038/s41584-018-0123-4

Ju, X. D., Deng, M., Ao, Y. F., Yu, C. L., Wang, J. Q., Yu, J. K., et al. (2010). The Protective Effect of Tetramethylpyrazine on Cartilage Explants and Chondrocytes. J. Ethnopharmacol 132 (2), 414-420. doi:10.1016/ j.jep.2010.08.020

Kamel, R., Abbas, H., and Shaffie, N. M. (2019). Development and Evaluation of PLA-Coated Co-micellar Nanosystem of Resveratrol for the Intra-articular Treatment of Arthritis. Int. J. Pharm. 569, 118560. doi:10.1016/ j.ijpharm.2019.118560

Kang, C., Jung, E., Hyeon, H., Seon, S., and Lee, D. (2020). Acid-activatable Polymeric Curcumin Nanoparticles as Therapeutic Agents for Osteoarthritis. Nanomedicine 23, 102104. doi:10.1016/j.nano.2019.102104

Kankala, R. K., Lu, F. J., Liu, C. G., Zhang, S. S., Chen, A. Z., and Wang, S. B. (2018). Effect of Icariin on Engineered 3D-Printed Porous Scaffolds for Cartilage Repair. Materials (Basel) 11 (8). doi:10.3390/ma11081390

Kann, B., Spengler, C., Coradini, K., Rigo, L. A., Bennink, M. L., Jacobs, K., et al. (2016). Intracellular Delivery of Poorly Soluble Polyphenols: Elucidating the Interplay of Self-Assembling Nanocarriers and Human Chondrocytes. Anal. Chem. 88 (14), 7014-7022. doi:10.1021/acs.analchem.6b00199

Kanzaki, N., Saito, K., Maeda, A., Kitagawa, Y., Kiso, Y., Watanabe, K., et al. (2012). Effect of a Dietary Supplement Containing Glucosamine Hydrochloride, Chondroitin Sulfate and Quercetin Glycosides on Symptomatic Knee Osteoarthritis: a Randomized, Double-Blind, Placebo-Controlled Study. J. Sci. Food Agric. 92 (4), 862-869. doi:10.1002/jsfa.4660

Kershenobich, D., Vargas, F., Garcia-Tsao, G., Perez Tamayo, R., Gent, M., and Rojkind, M. (1988). Colchicine in the Treatment of Cirrhosis of the Liver. N. Engl. J. Med. 318 (26), 1709-1713. doi:10.1056/NEJM198806303182602

Khan, M. A., and Tania, M. (2020). Cordycepin in Anticancer Research: Molecular Mechanism of Therapeutic Effects. Curr. Med. Chem. 27 (6), 983-996. doi:10.2174/0929867325666181001105749

Khayyal, M. T., El-Hazek, R. M., El-Sabbagh, W. A., Frank, J., Behnam, D., and Abdel-Tawab, M. (2018). Micellar Solubilisation Enhances the Antiinflammatory Activities of Curcumin and Boswellic Acids in Rats with Adjuvant-Induced Arthritis. Nutrition 54, 189-196. doi:10.1016/ j.nut.2018.03.055

Kim, H. A., and Blanco, F. J. (2007). Cell Death and Apoptosis in Osteoarthritic Cartilage. Curr. Drug Targets 8 (2), 333-345. doi:10.2174/ 138945007779940025

Kim, K. R., Park, K. K., Chun, K. S., and Chung, W. Y. (2010). Honokiol Inhibits the Progression of Collagen-Induced Arthritis by Reducing Levels of Proinflammatory Cytokines and Matrix Metalloproteinases and Blocking Oxidative Tissue Damage. J. Pharmacol. Sci. 114 (1), 69-78. doi:10.1254/ jphs.10070fp

Knieper, A. M., Klotsche, J., Lainka, E., Berger, T., Dressler, F., Jansson, A. F., et al. (2017). Familial Mediterranean Fever in Children and Adolescents: Factors for Colchicine Dosage and Predicting Parameters for Dose Increase. Rheumatology (Oxford) 56 (9), 1597-1606. doi:10.1093/rheumatology/kex222

Kotha, A., Sekharam, M., Cilenti, L., Siddiquee, K., Khaled, A., Zervos, A. S., et al. (2006). Resveratrol Inhibits Src and Stat 3 Signaling and Induces the Apoptosis of Malignant Cells Containing Activated Stat3 Protein. Mol. Cancer Ther. 5 (3), 621-629. doi:10.1158/1535-7163.MCT-05-0268

Kulsirirat, T., Honsawek, S., Takeda-Morishita, M., Sinchaipanid, N., Udomsinprasert, W., Leanpolchareanchai, J., et al. (2021). The Effects of Andrographolide on the Enhancement of Chondrogenesis and Osteogenesis in Human Suprapatellar Fat Pad Derived Mesenchymal Stem Cells. Molecules 26 (7). doi:10.3390/molecules 26071831

Kulsirirat, T., Sathirakul, K., Kamei, N., and Takeda-Morishita, M. (2021). The In Vitro and In Vivo Study of Novel Formulation of Andrographolide PLGA
Nanoparticle Embedded into Gelatin-Based Hydrogel to Prolong Delivery and Extend Residence Time in Joint. Int. J. Pharm. 602, 120618. doi:10.1016/ j.ijpharm.2021.120618

Kuptniratsaikul, V., Dajpratham, P., Taechaarpornkul, W., Buntragulpoontawee, M., Lukkanapichonchut, P., Chootip, C., et al. (2014). Efficacy and Safety of Curcuma Domestica Extracts Compared with Ibuprofen in Patients with Knee Osteoarthritis: a Multicenter Study. Clin. Interv. Aging 9, 451-458. doi:10.2147/ CIA.S58535

Leach, M. J., and Kumar, S. (2008). The Clinical Effectiveness of Ginger (Zingiber Officinale) in Adults with Osteoarthritis. JBI Libr. Syst. Rev. 6 (8), 310-323. doi:10.11124/01938924-200806080-00001

Lecanda, F., Avioli, L. V., and Cheng, S. L. (1997). Regulation of Bone Matrix Protein Expression and Induction of Differentiation of Human Osteoblasts and Human Bone Marrow Stromal Cells by Bone Morphogenetic Protein-2. J. Cel Biochem 67 (3), 386-396. doi:10.1002/(sici)1097-4644(19971201)67:3<386:aidjcb10 $>3.0 . c 0 ; 2-b$

Lee, S. W., Lee, H. J., Chung, W. T., Choi, S. M., Rhyu, S. H., Kim, D. K., et al. (2004). TRAIL Induces Apoptosis of Chondrocytes and Influences the Pathogenesis of Experimentally Induced Rat Osteoarthritis. Arthritis Rheum. 50 (2), 534-542. doi:10.1002/art.20052

Leong, D. J., Choudhury, M., Hanstein, R., Hirsh, D. M., Kim, S. J., Majeska, R. J., et al. (2014). Green tea Polyphenol Treatment Is Chondroprotective, Antiinflammatory and Palliative in a Mouse post-traumatic Osteoarthritis Model. Arthritis Res. Ther. 16 (6), 508. doi:10.1186/s13075-014-0508-y

Letter, M. (1974). Letter: Gouty Arthritis and Colchicine. N. Engl. J. Med. 291 (13), 681-682. doi:10.1056/NEJM197409262911320

Leung, Y. Y., Haaland, B., Huebner, J. L., Wong, S. B. S., Tjai, M., Wang, C., et al. (2018). Colchicine Lack of Effectiveness in Symptom and Inflammation Modification in Knee Osteoarthritis (COLKOA): a Randomized Controlled Trial. Osteoarthritis Cartilage 26 (5), 631-640. doi:10.1016/j.joca.2018.01.026

Li, B., Jiang, T., Liu, H., Miao, Z., Fang, D., Zheng, L., et al. (2018). Andrographolide Protects Chondrocytes from Oxidative Stress Injury by Activation of the Keap1Nrf2-Are Signaling Pathway. J. Cel Physiol 234 (1), 561-571. doi:10.1002/ jcp. 26769

Li, D., Yuan, T., Zhang, X., Xiao, Y., Wang, R., Fan, Y., et al. (2012). Icariin: a Potential Promoting Compound for Cartilage Tissue Engineering. Osteoarthritis Cartilage 20 (12), 1647-1656. doi:10.1016/j.joca.2012.08.009

Li, H., Zhuo, H., Yin, D., Li, W., Zhang, Y., Li, P., et al. (2021). Intra-Articular Injection of a Nanosuspension of Tetramethylpyrazine Dihydroxynaphthalenate for Stronger and Longer-Lasting Effects against Osteoarthritis. J. Biomed. Nanotechnol 17 (6), 1199-1207. doi:10.1166/jbn.2021.3094

Li, J., Shao, X., Wu, L., Feng, T., Jin, C., Fang, M., et al. (2011). Honokiol: an Effective Inhibitor of Tumor Necrosis Factor- $\alpha$-Induced Up-Regulation of Inflammatory Cytokine and Chemokine Production in Human Synovial Fibroblasts. Acta Biochim. Biophys. Sin (Shanghai) 43 (5), 380-386. doi:10.1093/abbs/gmr027

Li, W., Cai, L., Zhang, Y., Cui, L., and Shen, G. (2015). Intra-articular Resveratrol Injection Prevents Osteoarthritis Progression in a Mouse Model by Activating SIRT1 and Thereby Silencing HIF-2a. J. Orthop. Res. 33 (7), 1061-1070. doi:10.1002/jor.22859

Li, Z., Cheng, J., and Liu, J. (2020). Baicalin Protects Human OA Chondrocytes against IL-1 $\beta$-Induced Apoptosis and ECM Degradation by Activating Autophagy via MiR-766-3p/AIFM1 Axis. Drug Des. Devel Ther. 14, 2645-2655. doi:10.2147/DDDT.S255823

Lima, A. C., Ferreira, H., Reis, R. L., and Neves, N. M. (2019). Biodegradable Polymers: an Update on Drug Delivery in Bone and Cartilage Diseases. Expert Opin. Drug Deliv. 16 (8), 795-813. doi:10.1080/17425247.2019.1635117

Limagne, E., Lançon, A., Delmas, D., Cherkaoui-Malki, M., and Latruffe, N. (2016). Resveratrol Interferes with IL1- $\beta$-Induced Pro-inflammatory Paracrine Interaction between Primary Chondrocytes and Macrophages. Nutrients 8 (5). doi:10.3390/nu8050280

Lin, Z., Fu, C., Yan, Z., Wu, Y., Zhan, J., Lou, Z., et al. (2020). The Protective Effect of Hesperetin in Osteoarthritis: an In Vitro and In Vivo Study. Food Funct. 11 (3), 2654-2666. doi:10.1039/c9fo02552a

Liu, D., Tang, W., Zhang, H., Huang, H., Zhang, Z., Tang, D., et al. (2020). Icariin Protects Rabbit BMSCs against OGD-Induced Apoptosis by Inhibiting ERsMediated Autophagy via MAPK Signaling Pathway. Life Sci. 253, 117730. doi:10.1016/j.lfs.2020.117730 
Liu, D. D., Zhang, B. L., Yang, J. B., and Zhou, K. (2020). Celastrol Ameliorates Endoplasmic Stress-Mediated Apoptosis of Osteoarthritis via Regulating ATF6/CHOP Signalling Pathway. J. Pharm. Pharmacol. 72 (6), 826-835. doi:10.1111/jphp.13250

Liu, F., Wang, X., Han, X., Tan, X., and Kang, W. (2015). Cytotoxicity and DNA Interaction of Brucine and Strychnine-Two Alkaloids of Semen Strychni. Int. J. Biol. Macromol 77, 92-98. doi:10.1016/j.ijbiomac.2015.03.017

Liu, F. C., Hung, L. F., Wu, W. L., Chang, D. M., Huang, C. Y., Lai, J. H., et al. (2010). Chondroprotective Effects and Mechanisms of Resveratrol in Advanced Glycation End Products-Stimulated Chondrocytes. Arthritis Res. Ther. 12 (5), R167. doi:10.1186/ar3127

Liu, S. C., Lee, H. P., Hung, C. Y., Tsai, C. H., Li, T. M., and Tang, C. H. (2015). Berberine Attenuates CCN2-Induced IL-1 $\beta$ Expression and Prevents Cartilage Degradation in a Rat Model of Osteoarthritis. Toxicol. Appl. Pharmacol. 289 (1), 20-29. doi:10.1016/j.taap.2015.08.020

Liu, X., Machado, G. C., Eyles, J. P., Ravi, V., and Hunter, D. J. (2018). Dietary Supplements for Treating Osteoarthritis: a Systematic Review and MetaAnalysis. Br. J. Sports Med. 52 (3), 167-175. doi:10.1136/bjsports-2016-097333

Liu, Y., Mi, B., Lv, H., Liu, J., Xiong, Y., Hu, L., et al. (2018). Shared KEGG Pathways of Icariin-Targeted Genes and Osteoarthritis. J. Cel Biochem.

Lu, L., Hu, J., Wu, Q., An, Y., Cui, W., Wang, J., et al. (2019). Berberine Prevents Human Nucleus Pulposus Cells from IL-1 $\beta$-induced E-xtracellular M-atrix D-egradation and A-poptosis by I-nhibiting the NF- $\mathrm{kB}$ P-athway. Int. J. Mol. Med. 43 (4), 1679-1686. doi:10.3892/ijmm.2019.4105

Lu, L., Huang, R., Wu, Y., Jin, J. M., Chen, H. Z., Zhang, L. J., et al. (2020). Brucine: A Review of Phytochemistry, Pharmacology, and Toxicology. Front. Pharmacol. 11, 377. doi:10.3389/fphar.2020.00377

Ma, D., Yu, T., Peng, L., Wang, L., Liao, Z., and Xu, W. (2019). PIM1, CYP1B1, and HSPA2 Targeted by Quercetin Play Important Roles in Osteoarthritis Treatment by Achyranthes Bidentata. Evid. Based Complement. Alternat Med. 2019, 1205942. doi:10.1155/2019/1205942

Madry, H., Grün, U. W., and Knutsen, G. (2011). Cartilage Repair and Joint Preservation: Medical and Surgical Treatment Options. Dtsch Arztebl Int. 108 (40), 669-677. doi:10.3238/arztebl.2011.0669

Makris, E. A., Gomoll, A. H., Malizos, K. N., Hu, J. C., and Athanasiou, K. A. (2015). Repair and Tissue Engineering Techniques for Articular Cartilage. Nat. Rev. Rheumatol. 11 (1), 21-34. doi:10.1038/nrrheum.2014.157

Marwah, H., Garg, T., Goyal, A. K., and Rath, G. (2016). Permeation Enhancer Strategies in Transdermal Drug Delivery. Drug Deliv. 23 (2), 564-578. doi:10.3109/10717544.2014.935532

Mi, B., Wang, J., Liu, Y., Liu, J., Hu, L., Panayi, A. C., et al. (2018). Icariin Activates Autophagy via Down-Regulation of the NF-Kb Signaling-Mediated Apoptosis in Chondrocytes. Front. Pharmacol. 9, 605. doi:10.3389/fphar.2018.00605

Miller, R. E., Tran, P. B., Ishihara, S., Larkin, J., and Malfait, A. M. (2016). Therapeutic Effects of an Anti-ADAMTS-5 Antibody on Joint Damage and Mechanical Allodynia in a Murine Model of Osteoarthritis. Osteoarthritis Cartilage 24 (2), 299-306. doi:10.1016/j.joca.2015.09.005

Ming, L., Zhipeng, Y., Fei, Y., Feng, R., Jian, W., Baoguo, J., et al. (2018). Microfluidic-based Screening of Resveratrol and Drug-Loading PLA/ Gelatine Nano-Scaffold for the Repair of Cartilage Defect. Artif. Cell Nanomed Biotechnol 46 (Suppl. 1), 336-346. doi:10.1080/ 21691401.2017.1423498

Mishra, S., Verma, S. S., Rai, V., Awasthee, N., Chava, S., Hui, K. M., et al. (2019). Long Non-coding RNAs Are Emerging Targets of Phytochemicals for Cancer and Other Chronic Diseases. Cell Mol Life Sci 76 (10), 1947-1966. doi:10.1007/ s00018-019-03053-0

Mistry, H., Connock, M., Pink, J., Shyangdan, D., Clar, C., Royle, P., et al. (2017). Autologous Chondrocyte Implantation in the Knee: Systematic Review and Economic Evaluation. Health Technol. Assess. 21 (6), 1-294. doi:10.3310/ hta2 1060

Mohamed, A. L., Elmotasem, H., and Salama, A. A. A. (2020). Colchicine Mesoporous Silica Nanoparticles/hydrogel Composite Loaded Cotton Patches as a New Encapsulator System for Transdermal Osteoarthritis Management. Int. J. Biol. Macromol 164, 1149-1163. doi:10.1016/ j.ijbiomac.2020.07.133

Mok, S. W., Fu, S. C., Cheuk, Y. C., Chu, I. M., Chan, K. M., Qin, L., et al. (2020). Intra-Articular Delivery of Quercetin Using Thermosensitive Hydrogel
Attenuate Cartilage Degradation in an Osteoarthritis Rat Model. Cartilage 11 (4), 490-499. doi:10.1177/1947603518796550

Moon, P. D., Jeong, H. S., Chun, C. S., and Kim, H. M. (2011). Baekjeolyusin-tang and its Active Component Berberine Block the Release of Collagen and Proteoglycan from IL-1 $\beta$-stimulated Rabbit Cartilage and Down-Regulate Matrix Metalloproteinases in Rabbit Chondrocytes. Phytother Res. 25 (6), 844-850. doi:10.1002/ptr.3353

Muhammad, T., Ikram, M., Ullah, R., Rehman, S. U., and Kim, M. O. (2019). Hesperetin, a Citrus Flavonoid, Attenuates LPS-Induced Neuroinflammation, Apoptosis and Memory Impairments by Modulating TLR4/NF-Kb Signaling. Nutrients 11 (3). doi:10.3390/nu11030648

Munroe, M. E., Arbiser, J. L., and Bishop, G. A. (2007). Honokiol, a Natural Plant Product, Inhibits Inflammatory Signals and Alleviates Inflammatory Arthritis. J. Immunol. 179 (2), 753-763. doi:10.4049/jimmunol.179.2.753

Murphy, C. A., Garg, A. K., Silva-Correia, J., Reis, R. L., Oliveira, J. M., and Collins, M. N. (2019). The Meniscus in Normal and Osteoarthritic Tissues: Facing the Structure Property Challenges and Current Treatment Trends. Annu. Rev. Biomed. Eng. 21, 495-521. doi:10.1146/annurev-bioeng-060418-052547

Musumeci, G., Castrogiovanni, P., Trovato, F. M., Weinberg, A. M., Al-Wasiyah, M. K., Alqahtani, M. H., et al. (2015). Biomarkers of Chondrocyte Apoptosis and Autophagy in Osteoarthritis. Int. J. Mol. Sci. 16 (9), 20560-20575. doi:10.3390/ijms160920560

Natarajan, V., Madhan, B., and Tiku, M. L. (2015). Intra-Articular Injections of Polyphenols Protect Articular Cartilage from Inflammation-Induced Degradation: Suggesting a Potential Role in Cartilage Therapeutics. PLoS One 10 (6), e0127165. doi:10.1371/journal.pone.0127165

Nava, F., Ghilotti, F., Maggi, L., Hatemi, G., Del Bianco, A., Merlo, C., et al. (2014). Biologics, Colchicine, Corticosteroids, Immunosuppressants and InterferonAlpha for Neuro-Behçet's Syndrome. Cochrane Database Syst. Rev. (12), Cd010729. doi:10.1002/14651858.CD010729.pub2

Neag, M. A., Mocan, A., Echeverría, J., Pop, R. M., Bocsan, C. I., Crişan, G., et al. (2018). Berberine: Botanical Occurrence, Traditional Uses, Extraction Methods, and Relevance in Cardiovascular, Metabolic, Hepatic, and Renal Disorders. Front. Pharmacol. 9, 557. doi:10.3389/fphar.2018.00557

Oliveira Silva, M., Gregory, J. L., Ansari, N., and Stok, K. S. (2020). Molecular Signaling Interactions and Transport at the Osteochondral Interface: A Review. Front Cel Dev Biol 8, 750. doi:10.3389/fcell.2020.00750

Ouyang, Z., Tan, T., Liu, C., Duan, J., Wang, W., Guo, X., et al. (2019). Targeted Delivery of Hesperetin to Cartilage Attenuates Osteoarthritis by Bimodal Imaging with Gd2(CO3)3@PDA Nanoparticles via TLR-2/nf- $\mathrm{kB} / \mathrm{Akt}$ Signaling. Biomaterials 205, 50-63. doi:10.1016/j.biomaterials.2019.03.018

Ownby, S. L., Fortuno, L. V., Au, A. Y., Grzanna, M. W., Rashmir-Raven, A. M., and Frondoza, C. G. (2014). Expression of Pro-inflammatory Mediators Is Inhibited by an Avocado/soybean Unsaponifiables and Epigallocatechin Gallate Combination. J. Inflamm. (Lond) 11 (1), 8. doi:10.1186/1476-9255-11-8

Oz, B., Yildirim, A., Yolbas, S., Celik, Z. B., Etem, E. O., Deniz, G., et al. (2019). Resveratrol Inhibits Src Tyrosine Kinase, STAT3, and Wnt Signaling Pathway in Collagen Induced Arthritis Model. BioFactors 45 (1), 69-74. doi:10.1002/ biof. 1463

Pan, L., Zhang, Y., Chen, N., and Yang, L. (2017). Icariin Regulates Cellular Functions and Gene Expression of Osteoarthritis Patient-Derived Human Fibroblast-like Synoviocytes. Int. J. Mol. Sci. 18 (12). doi:10.3390/ijms18122656

Panahi, Y., Rahimnia, A. R., Sharafi, M., Alishiri, G., Saburi, A., and Sahebkar, A. (2014). Curcuminoid Treatment for Knee Osteoarthritis: a Randomized Double-Blind Placebo-Controlled Trial. Phytother Res. 28 (11), 1625-1631. doi: $10.1002 /$ ptr.5174

Parhiz, H., Roohbakhsh, A., Soltani, F., Rezaee, R., and Iranshahi, M. (2015). Antioxidant and Anti-inflammatory Properties of the Citrus Flavonoids Hesperidin and Hesperetin: an Updated Review of Their Molecular Mechanisms and Experimental Models. Phytother Res. 29 (3), 323-331. doi: $10.1002 /$ ptr.5256

Park, K. R., Kim, J. Y., Kim, E. C., Yun, H. M., and Hong, J. T. (2017). RANKL-induced Osteoclastogenesis Is Suppressed by 4-O-Methylhonokiol in Bone Marrow-Derived Macrophages. Arch. Pharm. Res. 40 (8), 933-942. doi:10.1007/s12272-017-0932-Z

Qin, L., He, Y., Zhao, X., Zhang, T., Qin, Y., and Du, A. (2020). Preparation, Characterization, and In Vitro Sustained Release Profile of Resveratrol-Loaded Silica Aerogel. Molecules 25 (12). doi:10.3390/molecules25122752 
Qin, N., Wei, L., Li, W., Yang, W., Cai, L., Qian, Z., et al. (2017). Local Intraarticular Injection of Resveratrol Delays Cartilage Degeneration in C57BL/6 Mice by Inducing Autophagy via AMPK/mTOR Pathway. J. Pharmacol. Sci. 134 (3), 166-174. doi:10.1016/j.jphs.2017.06.002

Qiu, B., Xu, X., Yi, P., and Hao, Y. (2020). Curcumin Reinforces MSC-Derived Exosomes in Attenuating Osteoarthritis via Modulating the miR-124/nf-kB and miR-143/ROCK1/TLR9 Signalling Pathways. J. Cel Mol Med 24 (18), 10855-10865. doi:10.1111/jcmm.15714

Qiu, L., Luo, Y., and Chen, X. (2018). Quercetin Attenuates Mitochondrial Dysfunction and Biogenesis via Upregulated AMPK/SIRT1 Signaling Pathway in OA Rats. Biomed. Pharmacother. 103, 1585-1591. doi:10.1016/ j.biopha.2018.05.003

Rahimi, M., Charmi, G., Matyjaszewski, K., Banquy, X., and Pietrasik, J. (2021). Recent Developments in Natural and Synthetic Polymeric Drug Delivery Systems Used for the Treatment of Osteoarthritis. Acta Biomater. 123, 31-50. doi:10.1016/j.actbio.2021.01.003

Rai, V., Dilisio, M. F., Dietz, N. E., and Agrawal, D. K. (2017). Recent Strategies in Cartilage Repair: A Systemic Review of the Scaffold Development and Tissue Engineering. J. Biomed. Mater. Res. A. 105 (8), 2343-2354. doi:10.1002/ jbm.a.36087

Rambaldi, A., and Gluud, C. (2005). Colchicine for Alcoholic and Non-alcoholic Liver Fibrosis and Cirrhosis. Cochrane Database Syst. Rev. (2), Cd002148. doi:10.1002/14651858.CD002148.pub2

Rasheed, Z., Rasheed, N., and Al-Shobaili, H. A. (2016). Epigallocatechin-3-Ogallate Up-Regulates microRNA-199a-3p Expression by Down-Regulating the Expression of Cyclooxygenase-2 in Stimulated Human Osteoarthritis Chondrocytes. J. Cel Mol Med 20 (12), 2241-2248. doi:10.1111/jcmm.12897

Ratanavaraporn, J., Soontornvipart, K., Shuangshoti, S., Shuangshoti, S., and Damrongsakkul, S. (2017). Localized Delivery of Curcumin from Injectable Gelatin/Thai Silk Fibroin Microspheres for Anti-inflammatory Treatment of Osteoarthritis in a Rat Model. Inflammopharmacology 25 (2), 211-221. doi:10.1007/s10787-017-0318-3

Rondanelli, M., Riva, A., Allegrini, P., Faliva, M. A., Naso, M., Peroni, G., et al. (2020). The Use of a New Food-Grade Lecithin Formulation of Highly Standardized Ginger (Zingiber Officinale) and Acmella Oleracea Extracts for the Treatment of Pain and Inflammation in a Group of Subjects with Moderate Knee Osteoarthritis. J. Pain Res. 13, 761-770. doi:10.2147/JPR.S214488

Sheu, S. Y., Chen, W. S., Sun, J. S., Lin, F. H., and Wu, T. (2013). Biological Characterization of Oxidized Hyaluronic Acid/resveratrol Hydrogel for Cartilage Tissue Engineering. J. Biomed. Mater. Res. A. 101 (12), 3457-3466. doi:10.1002/jbm.a.34653

Shi, Y., Hu, X., Cheng, J., Zhang, X., Zhao, F., Shi, W., et al. (2019). A Small Molecule Promotes Cartilage Extracellular Matrix Generation and Inhibits Osteoarthritis Development. Nat. Commun. 10 (1), 1914. doi:10.1038/s41467019-09839-x

Siard, M. H., McMurry, K. E., and Adams, A. A. (2016). Effects of Polyphenols Including Curcuminoids, Resveratrol, Quercetin, Pterostilbene, and Hydroxypterostilbene on Lymphocyte Pro-inflammatory Cytokine Production of Senior Horses In Vitro. Vet. Immunol. Immunopathol 173, 50-59. doi:10.1016/j.vetimm.2016.04.001

Singh, R., Ahmed, S., Malemud, C. J., Goldberg, V. M., and Haqqi, T. M. (2003). Epigallocatechin-3-gallate Selectively Inhibits Interleukin-1beta-Induced Activation of Mitogen Activated Protein Kinase Subgroup C-Jun N-Terminal Kinase in Human Osteoarthritis Chondrocytes. J. Orthop. Res. 21 (1), 102-109. doi:10.1016/S0736-0266(02)00089-X

Song, X., Zhang, Y., Dai, E., Du, H., and Wang, L. (2019). Mechanism of Action of Celastrol against Rheumatoid Arthritis: A Network Pharmacology Analysis. Int. Immunopharmacol 74, 105725. doi:10.1016/j.intimp.2019.105725

Sullivan, T. P., King, L. E., Jr., and Boyd, A. S. (1998). Colchicine in Dermatology. J. Am. Acad. Dermatol. 39 (6), 993-999. doi:10.1016/s0190-9622(98)70275-0

Tang, Y., Li, Y., Xin, D., Chen, L., Xiong, Z., and Yu, X. (2021). Icariin Alleviates Osteoarthritis by Regulating Autophagy of Chondrocytes by Mediating PI3K/ AKT/mTOR Signaling. Bioengineered 12 (1), 2984-2999. doi:10.1080/ 21655979.2021.1943602

Tao, X. M., Liu, P. F., Gu, H. Y., Lian, D. B., Gao, L., Tao, W. W., et al. (2020). Cordycepin Alleviates Anterior Cruciate Ligament Transection (ACLT)Induced Knee Osteoarthritis through Regulating TGF- $\beta$ Activity and Autophagy. Drug Des. Devel Ther. 14, 2809-2817. doi:10.2147/DDDT.S251893
Tasneem, S., Liu, B., Li, B., Choudhary, M. I., and Wang, W. (2019). Molecular Pharmacology of Inflammation: Medicinal Plants as Anti-inflammatory Agents. Pharmacol. Res. 139, 126-140. doi:10.1016/j.phrs.2018.11.001

Theodoridis, K., Manthou, M. E., Aggelidou, E., and Kritis, A. (2021). Vivo Cartilage Regeneration with Cell-Seeded Natural Biomaterial Scaffold Implants: 15-Year Study. Chengdu, China: Tissue Eng Part B Rev.

Vinatier, C., and Guicheux, J. (2016). Cartilage Tissue Engineering: From Biomaterials and Stem Cells to Osteoarthritis Treatments. Ann. Phys. Rehabil. Med. 59 (3), 139-144. doi:10.1016/j.rehab.2016.03.002

Wang, D., Miller, S. C., Liu, X. M., Anderson, B., Wang, X. S., and Goldring, S. R. (2007). Novel Dexamethasone-HPMA Copolymer Conjugate and its Potential Application in Treatment of Rheumatoid Arthritis. Arthritis Res. Ther. 9 (1), R2. doi:10.1186/ar2106

Wang, J., Wang, X., Cao, Y., Huang, T., Song, D. X., and Tao, H. R. (2018). Therapeutic Potential of Hyaluronic Acid/chitosan Nanoparticles for the Delivery of Curcuminoid in Knee Osteoarthritis and an In Vitro Evaluation in Chondrocytes. Int. J. Mol. Med. 42 (5), 2604-2614. doi:10.3892/ ijmm.2018.3817

Wang, M., Sampson, E. R., Jin, H., Li, J., Ke, Q. H., Im, H. J., et al. (2013). MMP13 Is a Critical Target Gene during the Progression of Osteoarthritis. Arthritis Res. Ther. 15 (1), R5. doi:10.1186/ar4133

Wang, P., Meng, Q., Wang, W., Zhang, S., Xiong, X., Qin, S., et al. (2020). Icariin Inhibits the Inflammation through Down-Regulating NF-Kb/hif-2a Signal Pathways in Chondrocytes. Biosci. Rep. 40 (11). doi:10.1042/BSR20203107

Wang, Q., Ye, C., Sun, S., Li, R., Shi, X., Wang, S., et al. (2019). Curcumin Attenuates Collagen-Induced Rat Arthritis via Anti-inflammatory and Apoptotic Effects. Int. Immunopharmacol 72, 292-300. doi:10.1016/ j.intimp.2019.04.027

Wang, R., Li, J., Xu, X., Xu, J., Jiang, H., Lv, Z., et al. (2021). Andrographolide Attenuates Synovial Inflammation of Osteoarthritis by Interacting with Tumor Necrosis Factor Receptor 2 Trafficking in a Rat Model. J. Orthop. Translat 29, 89-99. doi:10.1016/j.jot.2021.05.001

Wang, Z., Singh, A., Jones, G., Winzenberg, T., Ding, C., Chopra, A., et al. (2021). Efficacy and Safety of Turmeric Extracts for the Treatment of Knee Osteoarthritis: a Systematic Review and Meta-Analysis of Randomised Controlled Trials. Curr. Rheumatol. Rep. 23 (2), 11. doi:10.1007/s11926-02000975-8

Wang, Z. M., Chen, Y. C., and Wang, D. P. (2016). Resveratrol, a Natural Antioxidant, Protects Monosodium Iodoacetate-Induced Osteoarthritic Pain in Rats. Biomed. Pharmacother. 83, 763-770. doi:10.1016/j.biopha.2016.06.050

Wei, B., Zhang, Y., Tang, L., Ji, Y., Yan, C., and Zhang, X. (2019). Protective Effects of Quercetin against Inflammation and Oxidative Stress in a Rabbit Model of Knee Osteoarthritis. Drug Dev. Res. 80 (3), 360-367. doi:10.1002/ddr.21510

Wei, Y., Liu, J., Zhang, H., Du, X., Luo, Q., Sun, J., et al. (2016). Ligustrazine Attenuates Inflammation and the Associated Chemokines and Receptors in Ovalbumine-Induced Mouse Asthma Model. Environ. Toxicol. Pharmacol. 46, 55-61. doi:10.1016/j.etap.2016.07.005

Wildemann, B., Kadow-Romacker, A., Haas, N. P., and Schmidmaier, G. (2007), Quantification of Various Growth Factors in Different Demineralized Bone Matrix Preparations. J. Biomed. Mater. Res. A. 81 (2), 437-442. doi:10.1002/jbm.a.31085

Wong, S. K., Chin, K. Y., and Ima-Nirwana, S. (2020). Berberine and Musculoskeletal Disorders: The Therapeutic Potential and Underlying Molecular Mechanisms. Phytomedicine 73, 152892. doi:10.1016/ j.phymed.2019.152892

Wu, H., Yin, Z., Wang, L., Li, F., and Qiu, Y. (2017). Honokiol Improved Chondrogenesis and Suppressed Inflammation in Human Umbilical Cord Derived Mesenchymal Stem Cells via Blocking Nuclear Factor-Kb Pathway. BMC Cel Biol 18 (1), 29. doi:10.1186/s12860-017-0145-9

Wu, P., Liang, Q., Feng, P., Li, C., Yang, C., Liang, H., et al. (2017). A Novel Brucine Gel Transdermal Delivery System Designed for Anti-inflammatory and Analgesic Activities. Int. J. Mol. Sci. 18 (4). doi:10.3390/ijms18040757

Wu, Y., Lin, Z., Yan, Z., Wang, Z., Fu, X., and Yu, K. (2019). Sinomenine Contributes to the Inhibition of the Inflammatory Response and the Improvement of Osteoarthritis in Mouse-Cartilage Cells by Acting on the Nrf2/HO-1 and NF-Kb Signaling Pathways. Int. Immunopharmacol 75, 105715. doi:10.1016/j.intimp.2019.105715

Wu, Y., Lin, Z., Yan, Z., Wang, Z., Fu, X., and Yu, K. (2019). Sinomenine Contributes to the Inhibition of the Inflammatory Response and the 
Improvement of Osteoarthritis in Mouse-Cartilage Cells by Acting on the Nrf2/ HO-1 and NF-Kb Signaling Pathways. Int. Immunopharmacol 75, 105715. doi:10.1016/j.intimp.2019.105715

Xia, B., Di Chen, C., Zhang, J., Hu, S., Jin, H., and Tong, P. (2014). Osteoarthritis Pathogenesis: a Review of Molecular Mechanisms. Calcif Tissue Int. 95 (6), 495-505. doi:10.1007/s00223-014-9917-9

Xia, C., Chen, P., Mei, S., Ning, L., Lei, C., Wang, J., et al. (2017). Photo-crosslinked HAMA Hydrogel with Cordycepin Encapsulated Chitosan Microspheres for Osteoarthritis Treatment. Oncotarget 8 (2), 2835-2849. doi:10.18632/ oncotarget. 13748

Xinqiang, S., Yu, Z., Ningning, Y., Erqin, D., Lei, W., and Hongtao, D. (2020). Molecular Mechanism of Celastrol in the Treatment of Systemic Lupus Erythematosus Based on Network Pharmacology and Molecular Docking Technology. Life Sci. 240, 117063. doi:10.1016/j.lfs.2019.117063

Xu, B., Ye, J., Yuan, F. Z., Zhang, J. Y., Chen, Y. R., Fan, B. S., et al. (2020). Advances of Stem Cell-Laden Hydrogels with Biomimetic Microenvironment for Osteochondral Repair. Front. Bioeng. Biotechnol. 8, 247. doi:10.3389/fbioe.2020.00247

Yang, G., Chang, C. C., Yang, Y., Yuan, L., Xu, L., Ho, C. T., et al. (2018). Resveratrol Alleviates Rheumatoid Arthritis via Reducing ROS and Inflammation, Inhibiting MAPK Signaling Pathways, and Suppressing Angiogenesis. J. Agric. Food Chem. 66 (49), 12953-12960. doi:10.1021/ acs.jafc.8b05047

Yang, K. Y., Lin, L. C., Tseng, T. Y., Wang, S. C., and Tsai, T. H. (2007). Oral Bioavailability of Curcumin in Rat and the Herbal Analysis from Curcuma Longa by LC-MS/MS. J. Chromatogr. B Analyt Technol. Biomed. Life Sci. 853 (12), 183-189. doi:10.1016/j.jchromb.2007.03.010

Yeh, C. C., Su, Y. H., Lin, Y. J., Chen, P. J., Shi, C. S., Chen, C. N., et al. (2015). Evaluation of the Protective Effects of Curcuminoid (Curcumin and Bisdemethoxycurcumin)-Loaded Liposomes against Bone Turnover in a Cell-Based Model of Osteoarthritis. Drug Des. Devel Ther. 9, 2285-2300. doi:10.2147/DDDT.S78277

Yeung, A. W. K., Aggarwal, B. B., Orhan, I. E., Barreca, D., Battino, M., Belwal, T., et al. (2019). Resveratrol, a Popular Dietary Supplement for Human and Animal Health: Quantitative Research Literature Analysis - a Review. Anim. Sci. Pap. Rep. 37 (2), 103-118.

Yeung, A. W. K., Choudhary, N., Tewari, D., El-Demerdash, A., Horbanczuk, O. K., Das, N., et al. (2021). Quercetin: Total-Scale Literature Landscape Analysis of a Valuable Nutraceutical with Numerous Potential Applications in the Promotion of Human and Animal Health - a Review. Anim. Sci. Pap. Rep. 39 (3), 199-212.

Yin, W., Wang, T. S., Yin, F. Z., and Cai, B. C. (2003). Analgesic and Antiinflammatory Properties of Brucine and Brucine N-Oxide Extracted from Seeds of Strychnos Nux-Vomica. J. Ethnopharmacol 88 (2-3), 205-214. doi:10.1016/ s0378-8741(03)00224-1

Ying, X., Peng, L., Chen, H., Shen, Y., Yu, K., and Cheng, S. (2014). Cordycepin Prevented IL- $\beta$-induced Expression of Inflammatory Mediators in Human Osteoarthritis Chondrocytes. Int. Orthop. 38 (7), 1519-1526. doi:10.1007/ s00264-013-2219-4

Yuce, P., Hosgor, H., Rencber, S. F., and Yazir, Y. (2021). Effects of Intra-articular Resveratrol Injections on Cartilage Destruction and Synovial Inflammation in Experimental Temporomandibular Joint Osteoarthritis. J. Oral Maxillofac. Surg. 79 (2), 344-e12. doi:10.1016/j.joms.2020.09.015

Zeng, L., Yu, G., Hao, W., Yang, K., and Chen, H. (2021). The Efficacy and Safety of Curcuma Longa Extract and Curcumin Supplements on Osteoarthritis: a Systematic Review and Meta-Analysis. Biosci. Rep. 41 (6). doi:10.1042/BSR20210817

Zhang, X., Shi, Y., Zhang, Z., Yang, Z., and Huang, G. (2018). Intra-articular Delivery of Tetramethylpyrazine Microspheres with Enhanced Articular Cavity Retention for Treating Osteoarthritis. Asian J. Pharm. Sci. 13 (3), 229-238. doi:10.1016/j.ajps.2017.12.007

Zhang, Z., Leong, D. J., Xu, L., He, Z., Wang, A., Navati, M., et al. (2016). Curcumin Slows Osteoarthritis Progression and Relieves Osteoarthritis-Associated Pain
Symptoms in a post-traumatic Osteoarthritis Mouse Model. Arthritis Res. Ther. 18 (1), 128. doi:10.1186/s13075-016-1025-y

Zhao, H., Zhang, T., Xia, C., Shi, L., Wang, S., Zheng, X., et al. (2014). Berberine Ameliorates Cartilage Degeneration in Interleukin-1 $\beta$-Stimulated Rat Chondrocytes and in a Rat Model of Osteoarthritis via Akt Signalling. J. Cel Mol Med 18 (2), 283-292. doi:10.1111/jcmm.12186

Zhao, X. X., Peng, C., Zhang, H., and Qin, L. P. (2012). Sinomenium Acutum: a Review of Chemistry, Pharmacology, Pharmacokinetics, and Clinical Use. Pharm. Biol. 50 (8), 1053-1061. doi:10.3109/13880209.2012.656847

Zheng, Y., Xiao, L., Yu, C., Jin, P., Qin, D., Xu, Y., et al. (2019). Enhanced Antiarthritic Efficacy by Nanoparticles of (-)-Epigallocatechin GallateGlucosamine-Casein. J. Agric. Food Chem. 67 (23), 6476-6486. doi:10.1021/ acs.jafc.9b02075

Zhou, K., Hu, L., Liao, W., Yin, D., and Rui, F. (2016). Coptisine Prevented IL- $\beta$ Induced Expression of Inflammatory Mediators in Chondrocytes. Inflammation 39 (4), 1558-1565. doi:10.1007/s10753-016-0391-6

Zhou, Y., Liu, S., Ming, J., Li, Y., Deng, M., and He, B. (2017). Sustained Release Effects of Berberine-Loaded Chitosan Microspheres on In Vitro Chondrocyte Culture. Drug Dev. Ind. Pharm. 43 (10), 1703-1714. doi:10.1080/ 03639045.2017.1339076

Zhou, Y., Liu, S. Q., Yu, L., He, B., Wu, S. H., Zhao, Q., et al. (2015). Berberine Prevents Nitric Oxide-Induced Rat Chondrocyte Apoptosis and Cartilage Degeneration in a Rat Osteoarthritis Model via AMPK and P38 MAPK Signaling. Apoptosis 20 (9), 1187-1199. doi:10.1007/s10495015-1152-y

Zhou, Y., Tao, H., Li, Y., Deng, M., He, B., Xia, S., et al. (2016). Berberine Promotes Proliferation of Sodium Nitroprusside-Stimulated Rat Chondrocytes and Osteoarthritic Rat Cartilage via Wnt/B-Catenin Pathway. Eur. J. Pharmacol. 789, 109-118. doi:10.1016/j.ejphar.2016.07.027

Zhou, Y., Liu, S.-q., Peng, H., Yu, L., He, B., and Zhao, Q. (2015). In Vivo antiapoptosis Activity of Novel Berberine-Loaded Chitosan Nanoparticles Effectively Ameliorates Osteoarthritis. Int. Immunopharmacology 28 (1), 34-43. doi:10.1016/j.intimp.2015.05.014

Zhu, S., Chen, P., Chen, Y., Li, M., Chen, C., and Lu, H. (2020). 3D-Printed Extracellular Matrix/Polyethylene Glycol Diacrylate Hydrogel Incorporating the Anti-inflammatory Phytomolecule Honokiol for Regeneration of Osteochondral Defects. Am. J. Sports Med. 48 (11), 2808-2818. doi:10.1177/ 0363546520941842

Zuo, S., Zou, W., Wu, R. M., Yang, J., Fan, J. N., Zhao, X. K., et al. (2019). Icariin Alleviates IL-1 $\beta$-Induced Matrix Degradation by Activating the Nrf2/ARE Pathway in Human Chondrocytes. Drug Des. Devel Ther. 13, 3949-3961. doi:10.2147/DDDT.S203094

Conflict of Interest: The authors declare that the research was conducted in the absence of any commercial or financial relationships that could be construed as a potential conflict of interest.

Publisher's Note: All claims expressed in this article are solely those of the authors and do not necessarily represent those of their affiliated organizations, or those of the publisher, the editors, and the reviewers. Any product that may be evaluated in this article, or claim that may be made by its manufacturer, is not guaranteed or endorsed by the publisher.

Copyright $\odot 2022 \mathrm{Mu}$, Feng, Hu, Xiong, Ma and Tian. This is an open-access article distributed under the terms of the Creative Commons Attribution License (CC BY). The use, distribution or reproduction in other forums is permitted, provided the original author(s) and the copyright owner(s) are credited and that the original publication in this journal is cited, in accordance with accepted academic practice. No use, distribution or reproduction is permitted which does not comply with these terms. 